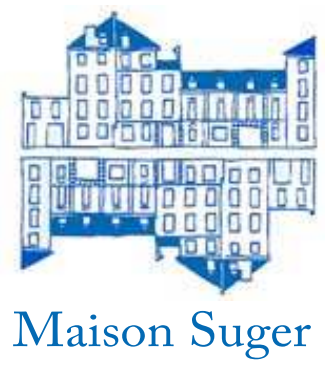

\title{
Pourquoi et jusqu'où la fuite en avant des agricultures sud-est asiatiques?
}

\author{
Rodolphe De Koninck \& Jean-François Rousseau
}

No13 | juin 2012

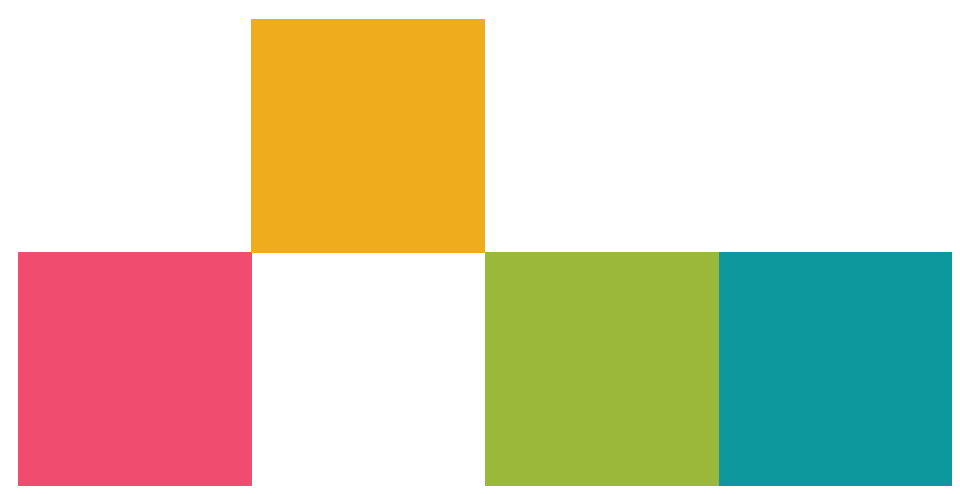

Depuis les années 1960, les agricultures de la majorité des pays qui composent le Sud-Est asiatique connaissent une très forte croissance. Alimentée essentiellement par une relation dynamique entre intensification et expansion territoriale, la forte hausse concerne la quasi-totalité des productions, qu'elles soient vivrières, riz en tête, ou commerciales, huile de palme, caoutchouc et café compris. Les succès rencontrés par l'ensemble du secteur agricole sont en bonne partie attribuables aux politiques des États concernés, qui, tour à tour, depuis un demi-siècle, l'ont favorisé en incitant d'un côté les agriculteurs à l'adoption des nouvelles technologies, celles de la Révolution verte, et de l'autre en investissant massivement dans la colonisation agricole des marges territoriales. 


\section{Pourquoi et jusqu'où la fuite en avant des agricultures sud-est asiatiques?}

\section{Rodolphe De Koninck \& Jean-François Rousseau}

Juin 2012

\section{Les auteurs}

Rodolphe De Koninck est professeur au Département de géographie de l'Université de Montréal et titulaire de la Chaire de recherche du Canada en études asiatiques

Jean-François Rousseau est doctorant au Département de géographie de l'Université McGill à Montréal.

\section{Le texte}

Les recherches sur lesquelles cet article est fondé ont été réalisées dans le cadre du projet intitulé Challenges of the Agrarian Transition in Southeast Asia (CHATSEA). Mené de 2004 à 2010, celui-ci a été appuyé financièrement par le Conseil des recherches en sciences humaines du Canada, dans le cadre de son programme des Grands travaux de recherche concertée. Les auteurs tiennent à remercier le Conseil tout comme la Maison Suger (Fondation Maison des sciences de l'homme) à Paris, ainsi que, parmi les nombreux participants à ce projet, Jean-Philippe Leblond, Pham Thanh Hai et Marc Girard.

Ce texte a été soumis en juin 2012 pour publication à la revue L’Espace géographique.

\section{Pour citer ce document}

Rodolphe De Koninck \& Jean-François Rousseau, Pourquoi et jusquioù la fuite en avant des agricultures sud-est asiatiques?, FMSH-WP-2012-13, juin 2012.

C Fondation Maison des sciences de l'homme - 2012

Informations et soumission des textes : wpfmsh@msh-paris.fr

Fondation Maison des sciences de l'homme 190-196 avenue de France 75013 Paris - France

http://www.msh-paris.fr http://halshs.archives-ouvertes.fr/FMSH-WP http://wpfmsh.hypotheses.org
Les Working Papers et les Position Papers de la Fondation Maison des sciences de l'homme ont pour objectif la diffusion ouverte des travaux en train de se faire dans le cadre des diverses activités scientifiques de la Fondation : Le Collège d'études mondiales, Bourses Fernand Braudel-IFER, Programmes scientifiques, hébergement à la Maison Suger, Séminaires et Centres associés, Directeurs d'études associés...

Les opinions exprimées dans cet article n'engagent que leur auteur et ne reflètent pas nécessairement les positions institutionnelles de la Fondation MSH.
The Working Papers and Position Papers of the FMSH are produced in the course of the scientific activities of the FMSH: the chairs of the Institute for Global Studies, Fernand Braudel-IFER grants, the Foundation's scientific programmes, or the scholars hosted at the Maison Suger or as associate research directors. Working Papers may also be produced in partnership with affiliated institutions.

The views expressed in this paper are the author's own and do not necessarily reflect institutional positions from the Foundation $\mathrm{MSH}$. 


\section{Résumé}

Depuis les années 1960, les agricultures de la majorité des pays qui composent le Sud-Est asiatique connaissent une très forte croissance. Alimentée essentiellement par une relation dynamique entre intensification et expansion territoriale, la forte hausse concerne la quasi-totalité des productions, qu'elles soient vivrières, riz en tête, ou commerciales, huile de palme, caoutchouc et café compris. Les succès rencontrés par l'ensemble du secteur agricole sont en bonne partie attribuables aux politiques des États concernés, qui, tour à tour, depuis un demi-siècle, l'ont favorisé en incitant d'un côté les agriculteurs à l'adoption des nouvelles technologies, celles de la Révolution verte, et de l'autre en investissant massivement dans la colonisation agricole des marges territoriales. Depuis quelques années, cette fuite en avant a atteint le domaine maritime, avec le développement rapide des productions halieutiques, dont celles issues de l'aquaculture marine. Il en résulte, premièrement, une détérioration environnementale accélérée, affectant tout particulièrement le patrimoine forestier, forêt de mangrove comprise, ainsi que les mers de la région. Deuxièmement, bien que l'expansion territoriale de l'agriculture vivrière ait jusqu'à récemment tenu tête à celle des cultures d'exportation, depuis peu ces dernières progressent nettement plus rapidement. Ce conditionnement au marché mondial s'accompagne d'un accroissement du rôle des multinationales de l'agriculture qui tendent à remplacer les États comme gestionnaires du domaine agricole, y compris les fronts pionniers.

\section{Mots-clés}

agriculture, intensification agricole, expansion agricole, détérioration environnementale, Asie du Sud-Est

\section{Why such Rapid Growth among Southeast Asian Agricultures?}

\section{Abstract}

Since the early 1960s, agricultural growth has been strong among most Southeast Asian countries. Largely fed by a dynamic relationship between agricultural intensification and territorial expansion, this strong growth concerns nearly all forms of production whether food or non-food, whether rice or cash crops such as palm oil, rubber or coffee. But the major factors behind these successes have been state policies. These have facilitated the adoption of new technologies among agricultural communities, particularly those associated with the Green Revolution as well as massive land opening towards the respective national territorial margins. More recently, this expansion has reached into the maritime domain, with the development of fish production including through marine aquaculture. This has led, first, to an acceleration of environmental deterioration which concerns in particular both the forest domain, including mangroves, and the maritime domain itself. Secondly, although until recently agricultural food production had held its ground so to speak, growing at equivalent speed with cash crop production, it is now beginning to fall behind. The growing submission of the region's agricultures to world market demand goes hand in hand with the increasing role played by agro-food multinationals which everywhere are replacing the states in monitoring the national agricultural domains, pioneer fronts included.

\section{Keywords}

agriculture, agricultural intensification, agricultural expansion, environnemental degradation, Southeast Asia 


\section{Sommaire}

Le modèle de développement sud-est asiatique 5

Où en sont le modèle et ses contradictions?

L'accélération de la fuite en avant 6

$\begin{array}{ll}\text { L'intensification agricole } & 6\end{array}$

$\begin{array}{ll}\text { L'expansion des terroirs agricoles } & 7\end{array}$

$\begin{array}{ll}\text { Produire pour tous les marchés } & 18\end{array}$

Un pari sur la terre et sur la mer

$\begin{array}{ll}\text { à la merci de la privatisation } & 18\end{array}$

Références 20

Liste des illustrations $\quad 22$ 


\section{Le modèle de}

\section{développement sud-est asiatique}

À compter de la fin des années 1950 et du début des années 1960, soit au début de la période postcoloniale, un véritable modèle de développement agricole sud-est asiatique a été mis en place (Carte 1). Dans un article paru en 2003, quelques était au cœur des succès économiques de la région (ibid., 306). La seconde hypothèse stipulait que l'évolution de ce modèle, reposant de plus en plus sur une véritable fuite en avant se traduisant par l'accentuation de la pression de l'agriculture sur le patrimoine territorial, risquait d'entraîner des conséquences irréversibles. En effet, on pouvait y voir une menace pour le potentiel de l'ensemble des territoires à supporter à long terme une crois-

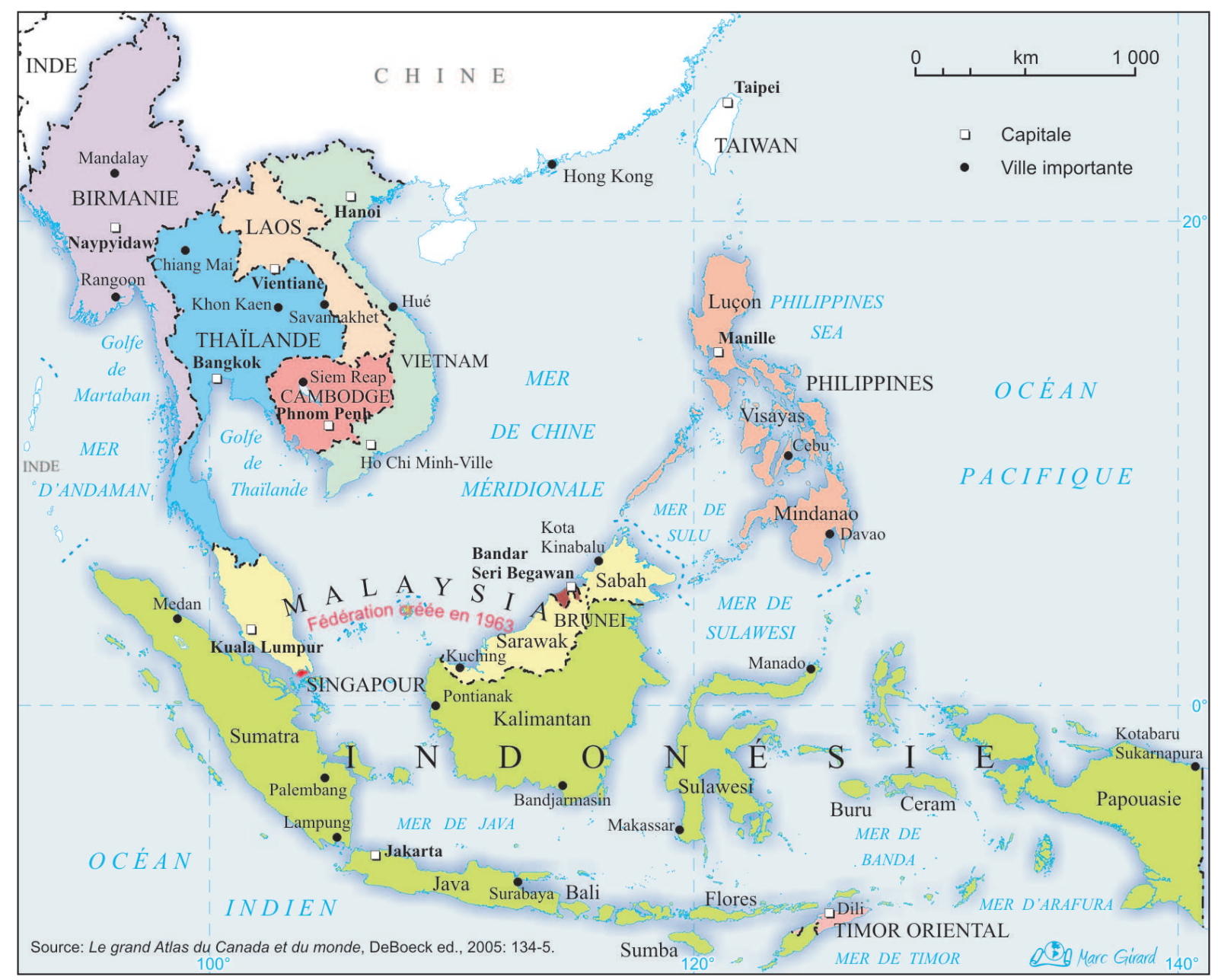

Carte 1. L'Asie du Sud-Est

interrogations et hypothèses avaient été émises au sujet de ce modèle (De Koninck, 2003) ${ }^{1}$. Nous rappelons ici deux de ces hypothèses. La première était qu'en l'absence de toute véritable réforme agraire, donc en opposition sur ce plan avec ce qui s'était déroulé après la Seconde Guerre mondiale au Japon, en Corée et à Taiwan, un modèle sud-est asiatique de développement agricole se caractérisant par une association dynamique entre intensification et expansion territoriale de l'agriculture

1. De Koninck R. (2003) « Les agricultures du Sud-Est asiatique : interrogations sur l'avenir d'un nouveau modèle de développement ». L'Espace Géographique, 32, 4, p. 301-10. sance économique soutenue. L’une des manifestations les plus évidentes de cette pression était un recul rapide de l'étendue du patrimoine forestier dans presque tous les pays impliqués dans cette association dynamique entre intensification et expansion.

\section{Où en sont le modèle et ses contradictions?}

Sur la base d'investigations récentes, il apparaît que ce modèle n'a depuis cessé de se consolider. Lexpansion du domaine agricole de l'Asie $\mathrm{du}$ Sud-Est continue à s'y conjuguer avec 

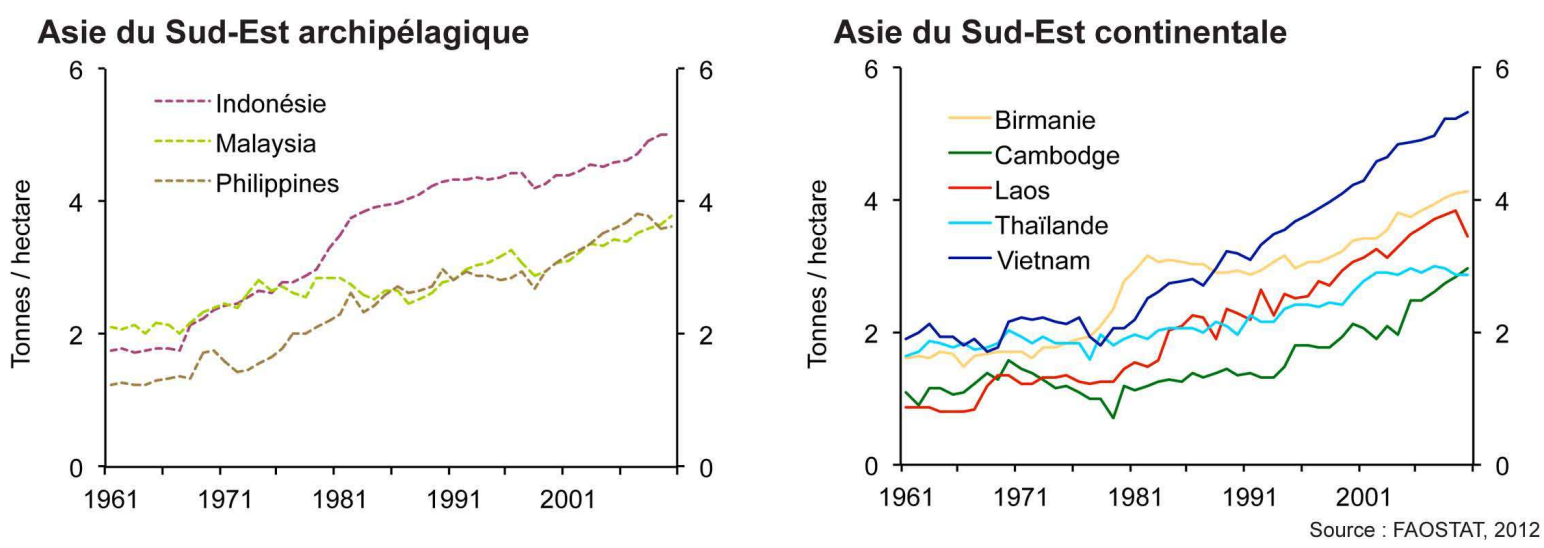

Figure 1 : Rendements rizicoles, 1961-2010

l'intensification des pratiques culturales, celle-ci entraînant de fortes hausses des rendements, dans l'agriculture tant vivrière que commerciale, tant parmi les petits producteurs parcellaires que dans les grandes plantations (De Koninck et Rousseau, 2012). Cela semble représenter un processus quasi inégalé dans le monde, à part peut-être au Brésil, seul autre pays où une évolution au moins partiellement comparable serait en cours. En effet, il n'y a pas de doute que l'expansion du domaine agricole brésilien bat son plein, là aussi essentiellement aux dépens du patrimoine forestier, alors qu'au plan de la hausse des rendements agricoles les performances soient à peu près équivalentes ${ }^{2}$. Il faut aussi ajouter que le dynamisme de l'agriculture du géant sud-américain repose en partie sur celui de l'élevage bovin et de la demande toujours plus grande en pâturages et en fourrages, alors qu'en Asie du Sud-Est, région où l'élevage extensif est fort peu pratiqué, ce sont les cultures vivrières et de rente qui occupent la quasi-totalité des superficies agricoles ${ }^{3}$.

À ce jour, le modèle sud-est asiatique semble être parvenu à éviter que les contradictions que nous

2. Au Brésil, depuis le début des années 1960, les rendements sucriers ont presque doublé alors que les rendements céréaliers ont plus que triplé. En Asie du Sud-Est, la hausse des rendements pour les principales cultures commerciales (huile de palme, caoutchouc, café) a varié selon les pays entre doublement et triplement. Quant à ceux obtenus dans la riziculture, ils ont, là aussi à l'échelle régionale, presque triplé.

3. Notre étude ne concerne que les huit grands pays agricoles de la région. Nous laissons de côté la cité-État de Singapour, le sultanat de Brunei où l'agriculture est encore plus marginale, et enfin le Timor oriental où, bien qu'elle ne le soit pas, peu de données longitudinales et diachroniques fiables sont disponibles, en particulier pour la période que nous avons choisi d'étudier, soit 1960-2010. Au total, ces huit pays rassemblent quelque $98 \%$ de la population du Sud-Est asiatique et comptent pour à peu près la même proportion des terres qui le composent. avions soulignées en 2003 n'entraînent son déclin. Tant l'agriculture que l'aquaculture continuent à s'intensifier et à s'étendre sur des territoires de plus en plus éloignés des centres de population régionaux et intouchés jusqu'à récemment, tels des massifs montagneux et des littoraux à mangrove, de même qu'au sein d'environnements proprement maritimes, parfois loin au cœur des mers de la région.

\section{L'accélération de la fuite en avant}

En effet, non seulement cette intensification et cette expansion s'amplifient, mais leurs conséquences sont de plus en plus manifestes sur plusieurs plans.

\section{L'intensification agricole}

Depuis le début des années 1960, alors que dans plusieurs pays, notamment l'Indonésie, les Philippines et la Malaysia, les agences agricoles nationales commencèrent à favoriser l'application des politiques dites de la révolution verte (Barker et al., 1985), d'abord et avant tout dans la riziculture, les rendements agricoles n'ont cessé de croître de plus en plus rapidement (Figure 1$)^{4}$. Le rythme et l'ampleur de cette croissance n'ont certes pas été uniformes, certains pays, en particulier ceux du continent, ayant pris quelque retard au départ.

4. L'ensemble des figures publiées ici ont été réalisées à l'aide de données colligées auprès de bases de données maintenues par des organismes internationaux, à commencer par la FAO (http://faostat.fao.org/) et la CNUCED (http://www. unctadxii.org/fr/Statistiques/). Les réserves que nous avons énoncées ailleurs à propos de l'utilisation de telles données statistiques demeurent valables dans le cas présent (De Koninck et Rousseau, 2012). Il en va de même de notre constat préalable que ces informations sont, à l'heure actuelle, les seules disponibles pour dresser un portrait de l'évolution à long terme du domaine agricole sud-est asiatique. 

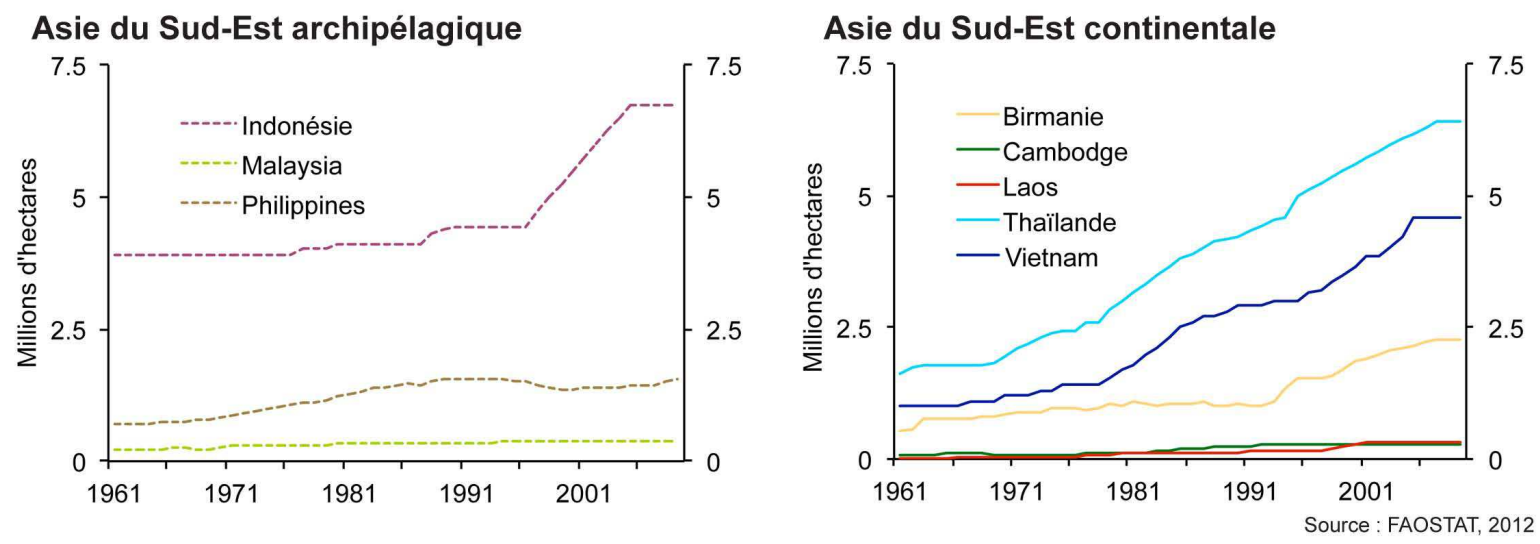

Figure 2 : Superficie équipée de systèmes d'irrigation, 1961-2009

Mais tous, ce qui comprend le Vietnam de façon remarquable depuis l'application à compter du milieu des années 1980 de réformes économiques de type capitaliste - dans le contexte de ce qu'il est convenu d'appeler le Doi Moi ou renouveau - se sont à leur tour lancés dans l'intensification agricole. Celle-ci était fondée sur l'utilisation de variétés de semences hybrides et le recours massif aux intrants d'origine industrielle, associés en général à une amélioration voire une extension systématiques des infrastructures d'irrigation (Figure 2). Cet accroissement des superficies suffisamment irriguées pour permettre la double récolte a été exceptionnel et participe à la hausse des rendements par récolte. S'ensuit un important surplus rizicole régional, provenant surtout de la Thailande et du Vietnam, ces pays étant par ailleurs - demeuré dans le premier cas et devenu dans le second - les deux plus importants exportateurs de riz au monde.

Au total, la croissance de la production rizicole a été forte presque partout, hormis en Malaysia, là où l'État a plutôt choisi de favoriser l'intensification et l'expansion du palmier à huile. Ainsi,

\section{Asie du Sud-Est archipélagique}

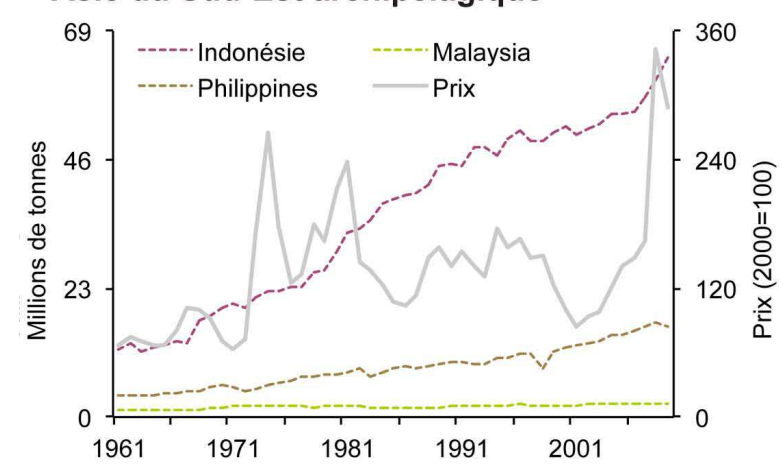

en Indonésie, de loin le pays le plus étendu et le plus peuplé de la région, la production rizicole, entre 1961 et 2010, a été multiplié par plus de cinq que alors que la population ne l'était que par 2,5 (Figure 3). D'ailleurs, pendant la même période de près d'un demi-siècle, cette forte supériorité de la croissance de la production rizicole sur celle de la population a été atteinte dans tous les pays - hormis ici encore en Malaysia - les plus performants sur ce plan ayant été, dans l'ordre, le Laos, l'Indonésie, les Philippines, la Birmanie et le Vietnam.

\section{L'expansion des terroirs agricoles}

Bien que la part des territoires nationaux consacrée au riz, qui demeure la première culture et le premier aliment dans la région, ait partout (Malaysia exceptée) fait l'objet d'une augmentation, c'est surtout par celle des superficies récoltées - essentiellement grâce à la double récolte et épisodiquement la triple récolte annuelle - que les rizières ont gagné du terrain, en quelque sorte. D'autres cultures vivrières, notamment celle du maïs et de la majorité des fruits et légumes, ont aussi largement progressé territorialement,

\section{Asie du Sud-Est continentale}

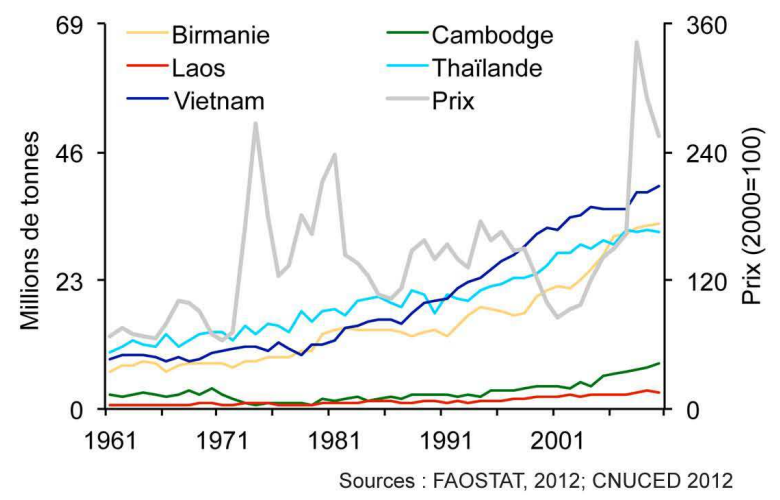

Figure 3 : Production rizicole et prix, 1961-2010 

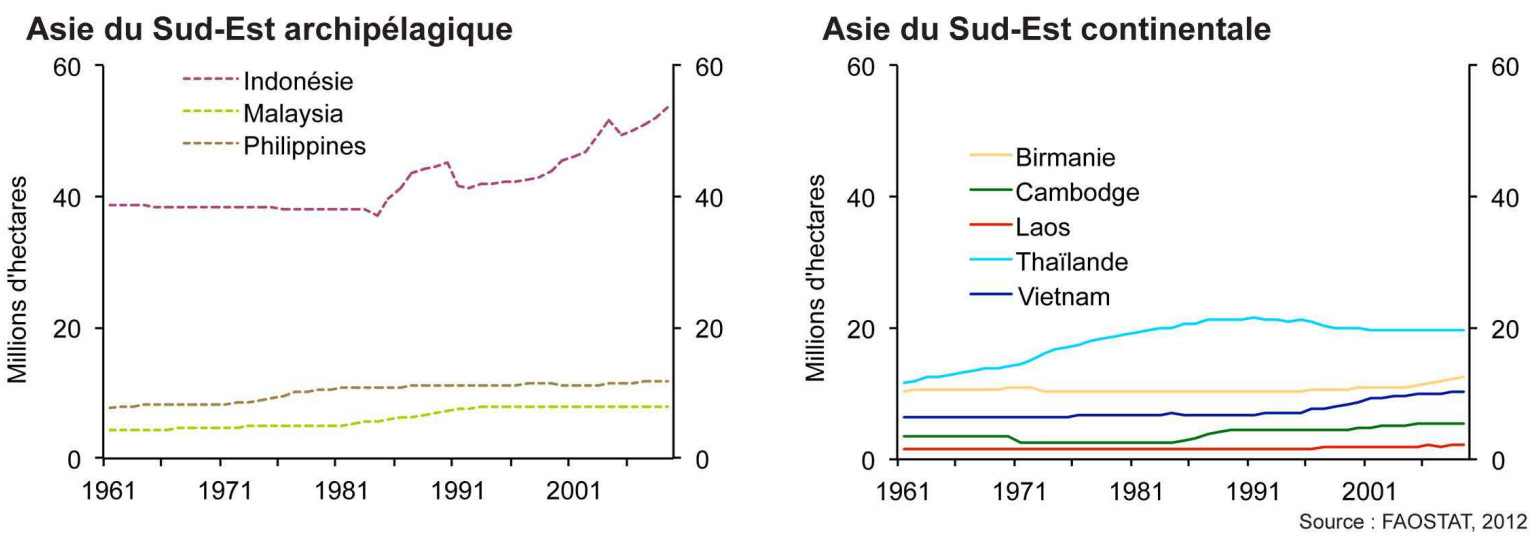

Figure 4 : Superficie agricole, 1961-2009
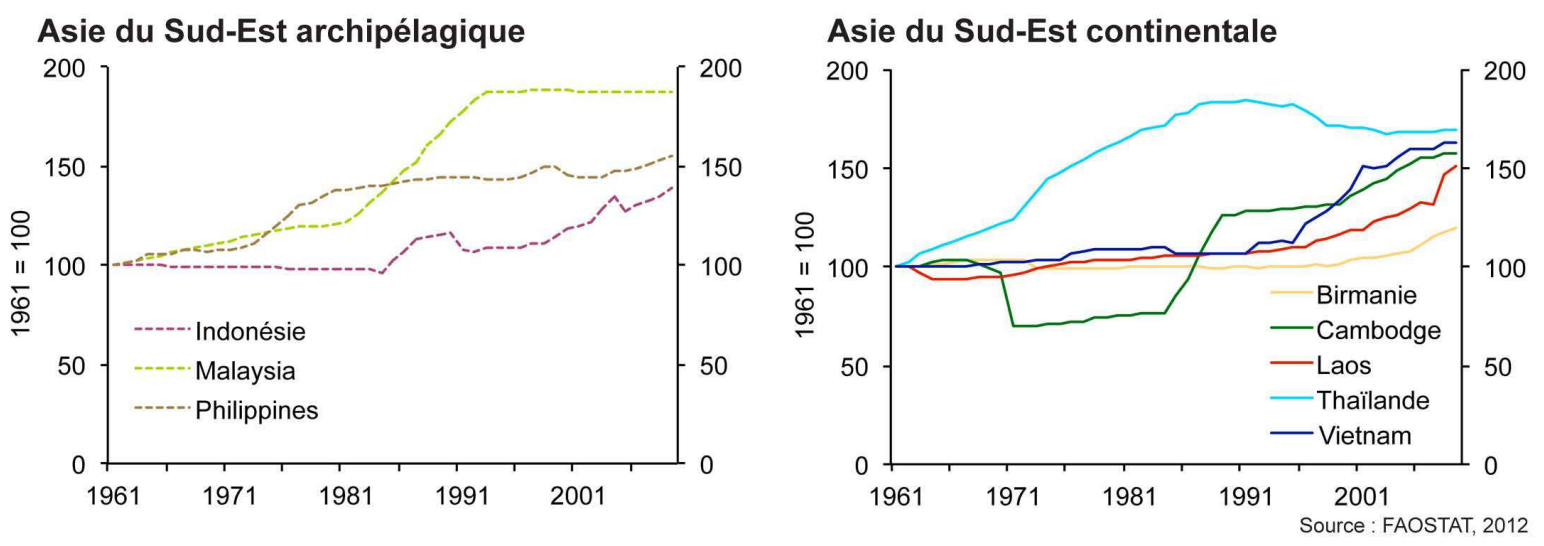

Figure 5 : Croissance relative des superficies agricoles, 1961-2009

proportionnellement plus encore que le riz. Mais les principales cultures impliquées dans l'expansion territoriale de l'agriculture - en particulier dans les zones périphériques ou marginales laquelle depuis les années 1960 a été plus forte que partout ailleurs dans le monde à l'exception du Brésil (De Koninck, 2011), ont été celles des cultures de rente ou si l'on préfère les cultures commerciales. Et parmi celles-ci, c'est le palmier à huile qui a mené la charge. À ce sujet, on peut dresser six constats majeurs.

1. L'expansion agricole concerne tous les pays de la région étudiés ici. Par ailleurs, tout comme l'intensification, celle-ci ne s'est pas réalisée partout au même rythme (Figures 4 et 5). Au cours des années 1960 et 1970, ce sont surtout la Thailande et les Philippines qui ont été concernées, cette expansion ayant par ailleurs été entamée beaucoup plus tôt dans les deux pays ${ }^{5}$. Mais il a fallu

5. Rappelons que le Sud-Est asiatique dans son ensemble a connu plusieurs types et plusieurs phases d'expansion agricole, y compris pendant la période coloniale (De Koninck, 2011; De Koninck et Rousseau, 2012). attendre les années 1980 avant que le géant de la région, l'Indonésie, ne relance à son tour une dynamique là aussi fort ancienne. En effet, à compter du milieu du XIXe siècle, l'administration coloniale néerlandaise avait favorisé un accroissement fort et soutenu des superficies cultivées à travers une large partie du domaine sous son contrôle (Geertz, 1963). Par contre, cette fois-ci, c'est-àdire depuis une trentaine d'années, l'Indonésie met les bouchées doubles : son agriculture gagne plus de 300000 hectares en moyenne annuellement, presque entièrement aux dépens des forêts. Quant au Vietnam, dont l'essor agricole date de la période du renouveau économique précité, c'est lui qui, depuis les années 1990, connaît le plus fort taux d'expansion de ses terres agricoles. Mais ni la Birmanie, ni le Laos, ni le Cambodge ne sont pour autant en reste, l'agriculture de ce dernier pays ayant fait l'objet depuis le début des années 1980 d'une poussée expansionniste dont l'ampleur apparaît inversement proportionnelle à celle de son effondrement pendant le règne des Khmers rouges (1975-79). Même cas de figure en Malaysia, dont l'économie s'industrialise plus 
Tableau 1 :

Pourcentage des superficies nationales consacrées à l'agriculture, 1961-2009

$\begin{array}{lrrrrrr} & 1961-3 & 1971-3 & 1981-3 & 1991-3 & 2001-3 & 2009 \\ \text { Cambodge } & 15 \% & 16 \% & 15 \% & 15 \% & 16 \% & 18 \% \\ \text { Laos } & 20 \% & 14 \% & 15 \% & 25 \% & 28 \% & 31 \% \\ \text { Birmanie } & 6 \% & 6 \% & 7 \% & 7 \% & 8 \% & 10 \% \\ \text { Thaïlande } & 23 \% & 30 \% & 38 \% & 42 \% & 38 \% & 39 \% \\ \text { Vietnam } & 19 \% & 19 \% & 21 \% & 21 \% & 29 \% & 31 \% \\ & & & & & & \\ \text { Indonésie } & 1961-3 & 1971-3 & 1981-3 & 1991-3 & 2001-3 & 2009 \\ \text { Malaysia } & 20 \% & 20 \% & 20 \% & 22 \% & 25 \% & 28 \% \\ \text { Philippines } & 13 \% & 14 \% & 16 \% & 23 \% & 24 \% & 24 \% \\ & 26 \% & 28 \% & 36 \% & 37 \% & 37 \% & 40 \%\end{array}$

rapidement que celle des tous ses voisins, ce qui pourrait laisser présager la marginalisation de son agriculture. Pourtant, il n'en est rien! La Malaysia a notamment laissé libre cours au développement de l'industrie du palmier à huile, dont la culture s'est massivement étendue, surtout depuis les années 1980, tant dans la péninsule, la Malaisie proprement dite, que dans le Sabah et le Sarawak, ces États malaysiens « extérieurs » situés dans l'île de Bornéo (De Koninck et al., 2011). Seule la Thailande, dont près de $40 \%$ du territoire national sont encore consacrés à l'agriculture - proportion égalée seulement aux Philippines - semble vouloir mettre un terme à l'expansion agricole. Au total, ce sont aujourd'hui six de ces huit pays de la région qui consacrent entre $25 \%$ et $40 \%$ de leur territoire à l'agriculture, ce qui témoigne d'une intensité agricole désormais presque comparable à celle de l'Europe (Tableau 1)

2. Plusieurs cultures de rente sont concernées. Certes, c'est l'expansion de la culture du palmier à huile

qui depuis les années 1980 s'avère la plus spectaculaire et qui fait les manchettes (Figures 6 et 7). Mais des gains territoriaux ont également été réalisés pour celles - par ordre d'importance des superficies concernées et pour ne mentionner que les principales - de l'hévéa, du cocotier, du caféier, du cacaotier, du théier et même de la canne à sucre. (Tableau 2).

La culture la plus rentable, celle du palmier à huile, est largement concentrée en Malaysia et en Indonésie, de loin les deux leaders mondiaux, de meilleurs rendements étant obtenus dans la première, la seconde compensant par une expansion plus rapide des superficies cultivées. Quant à la culture de l'hévéa, elle aussi d'abord et avant tout sud-est asiatique - l'ensemble de la région répondant aujourd'hui encore à presque 90\% de la demande mondiale - demeurant surtout l'affaire de ces deux mêmes pays et de plus en plus de la Thailande, celle-ci ayant désormais dépassé la Malaysia sur le marché des exportations de

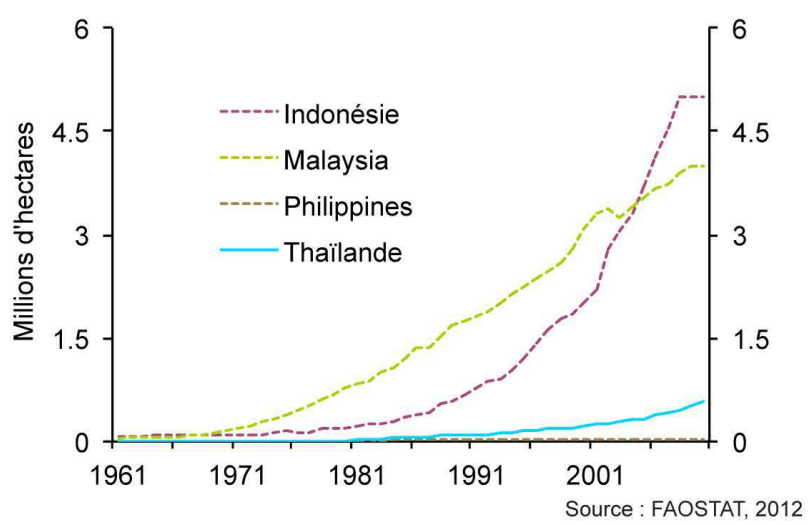

Figure 6 : Superficies consacrées au palmier à huile, principaux producteurs, 1961-2010 

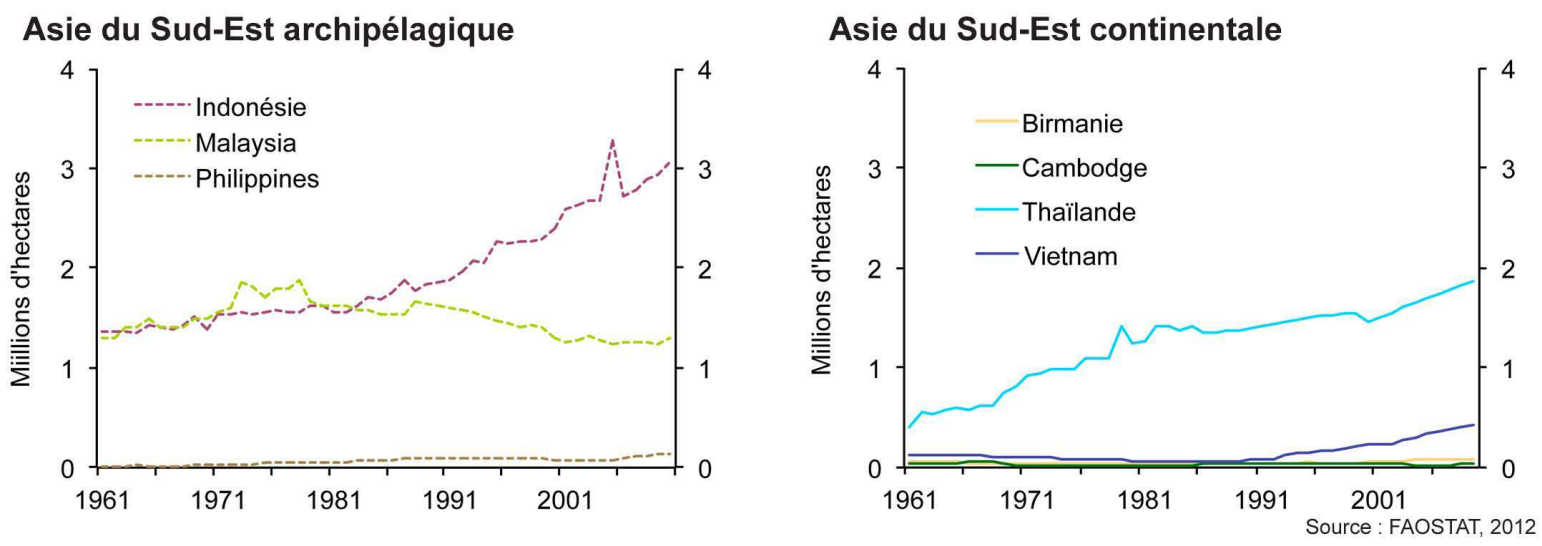

Figure 7 : Superficies consacrées à l'hévéa, principaux producteurs, 1961-2010

\section{Tableau 2 : \\ Superficies consacrées aux principales cultures (millions d'hectares)}

$\begin{array}{lcrrrrrr} & & & & & & & \begin{array}{r}\text { Croissance } \\ (2010 /\end{array} \\ & 1961-3 & 1971-3 & 1981-3 & 1991-3 & 2001-3 & 2010 & 1961-3) \\ \text { Riz } & 29.2 & 31.1 & 34.9 & 37.7 & 42.9 & 48.5 & 1.7 \\ \text { Maïs } & 5.5 & 6.6 & 8.0 & 8.6 & 8.1 & 9.8 & 1.8 \\ \text { Cacao } & 0.0 & 0.0 & 0.1 & 0.6 & 0.9 & 1.1 & 60.7 \\ \text { Noix de coco } & 2.9 & 4.0 & 5.9 & 6.3 & 6.5 & 7.1 & 2.4 \\ \text { Café } & 0.3 & 0.4 & 0.7 & 1.1 & 2.1 & 2.0 & 6.9 \\ \text { Caoutchouc } & 3.4 & 4.3 & 4.7 & 5.2 & 5.9 & 7.0 & 2.0 \\ \text { Huile de palme } & 0.1 & 0.3 & 1.2 & 2.9 & 6.3 & 9.6 & 80.8 \\ \text { Canne à sucre } & 0.5 & 0.8 & 1.4 & 1.9 & 2.2 & 2.2 & 4.8 \\ \text { Thé } & 0.2 & 0.2 & 0.2 & 0.2 & 0.3 & 0.3 & 1.8\end{array}$

caoutchouc, étant même en voie de devancer l'Indonésie. C'est que, à vrai dire, malgré la persistance de la plupart des grandes spécialisations commerciales, la géographie régionale des cultures de rente est en constante transformation.

\section{En effet, spécialisation, diversification, partage et} transfert des responsabilités se succèdent et se relaient. S'agissant de cultures commerciales et de spécialisation, on voit bien que chaque pays concentre ses efforts sur l'une ou quelques-unes d'entre elles. La répartition géographique de telle ou telle culture subit de fréquents ajustements et, souvent, elle déborde chez les voisins. Ainsi, alors que la Malaysia se désengage progressivement de son rôle de leader dans la culture de l'hévéa, tout en demeurant très impliquée dans la transformation du latex en caoutchouc et produits dérivés, elle continue à favoriser l'expansion du palmier à huile sur son territoire. À un point tel que les superficies recouvertes par celui-ci comptent pour près de la moitié de toutes celles réservées à l'agriculture, dans un pays qui y consacre tout de même près du quart de son territoire. Ce désengagement relatif s'accompagne d'une forte progression de l'hévéaculture dans le sud de la Thailande, tout comme en Indonésie et dans les trois autres pays de la péninsule, notamment au Vietnam et dans le nord du Laos dans ce cas en réponse à la forte demande en provenance du grand voisin chinois.

Mais il n'y a pas que l'hévéaculture qui fasse l'objet d'une redistribution des cartes. Bien que l'Indonésie et la Malaysia dominent outrageusement le secteur de la production et de l'exportation de l'huile de palme - les deux pays répondant à eux seuls à quelque $85 \%$ d'une demande mondiale en forte croissance - la culture du palmier à huile se répand également ailleurs dans la région. Pour le moment, les pays les plus concernés sont la Thailande, les Philippines et même le Cambodge, là où des investisseurs malaysiens sont impliqués, 
tout comme ils le sont de plus en plus ailleurs dans le monde, notamment en Papouasie-Nouvelle-Guinée et en Afrique.

Le café est une autre culture de rente à avoir connu une très forte expansion au cours des dernières décennies. On oublie parfois combien cette culture était déjà très répandue dans la région à l'époque coloniale. Elle était non seulement présente dans tous les pays du continent, Birmanie, Thailande et Indochine française comprises, en particulier sur les Hautes Terres du centre du Vietnam et du sud laotien, mais aussi aux Philippines, en Malaysia et, surtout, en Indonésie. Ce dernier pays, où la culture du café fut initiée à Java dès 1699 (Neilson, 2008), est longtemps demeuré et de très loin le premier producteur de la région, voire de l'Asie. À compter des années 1960, la demande mondiale en café a commencé à crôitre très rapidement et à doper la croissance de la production indonésienne. Puis vint le tour du Vietnam dont la production allait, à compter de la fin des années 1980, connaître un véritable boom, lequel d'ailleurs perdure aujourd'hui malgré les

\section{Asie du Sud-Est archipélagique}

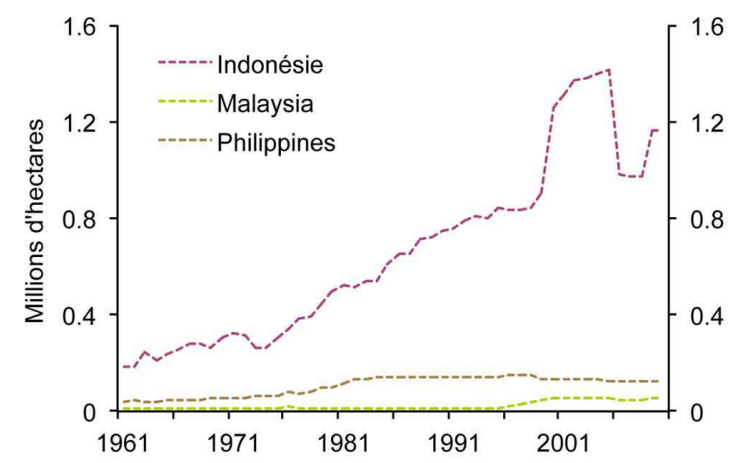

fortes fluctuations des prix du café (Figures 8, 9 et 10). Cet essor combine une expansion fulgurante des fronts pionniers sur les Plateaux centraux du pays (Fortunel, 2000; Hardy, 2003), largement consacrés à la caféiculture, tout comme sur une hausse presque aussi prononcée des rendements, aujourd'hui trois plus élevés qu'en Indonésie. En résulte une production vietnamienne désormais la deuxième plus volumineuse au monde, mais néanmoins loin derrière celle du Brésil, pays tout de même 26 fois plus étendu. Bien sûr, le café produit au Vietnam, essentiellement du robusta, n'est pas de la meilleure qualité. Mais il n'en demeure pas moins que les petits producteurs parcellaires vietnamiens ont confirmé cette propension des paysans du Sud-Est asiatique à souscrire aux dynamiques pionnières et à contribuer de façon très significative aux exportations vers les marchés internationaux.

Une autre culture de rente a connu un boom récent dans la région : celle du cacao. Essentiellement pratiquée dans les seuls pays de l'archipel, la culture du cacaotier a d'abord fait l'objet d'une très
Asie du Sud-Est continentale

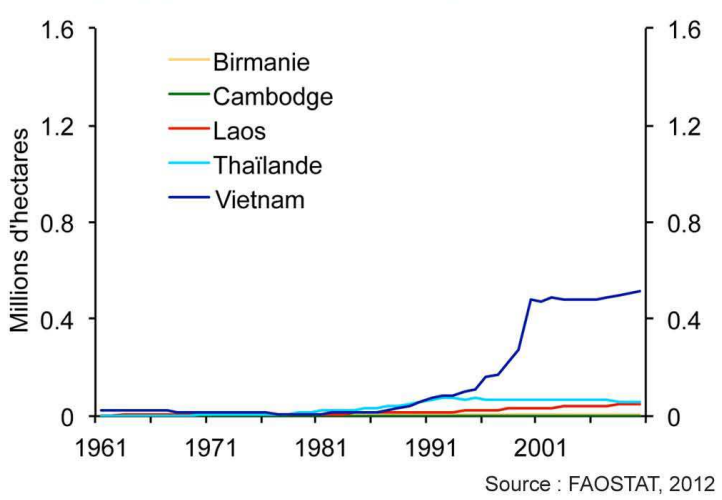

Figures 8 : Superficies consacrées au café, 1961-2010

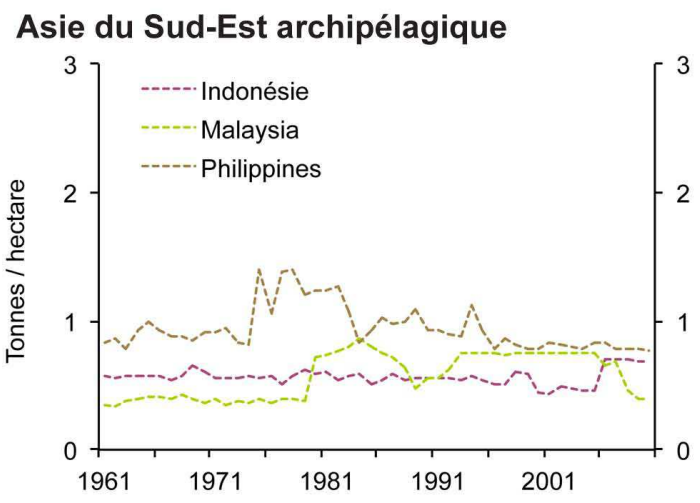

Asie du Sud-Est continentale

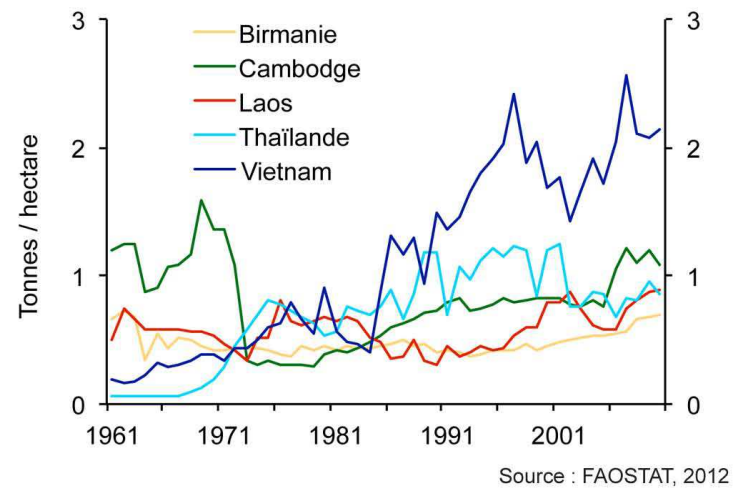

Figure 9 : Rendements caféiers, 1961-2010 

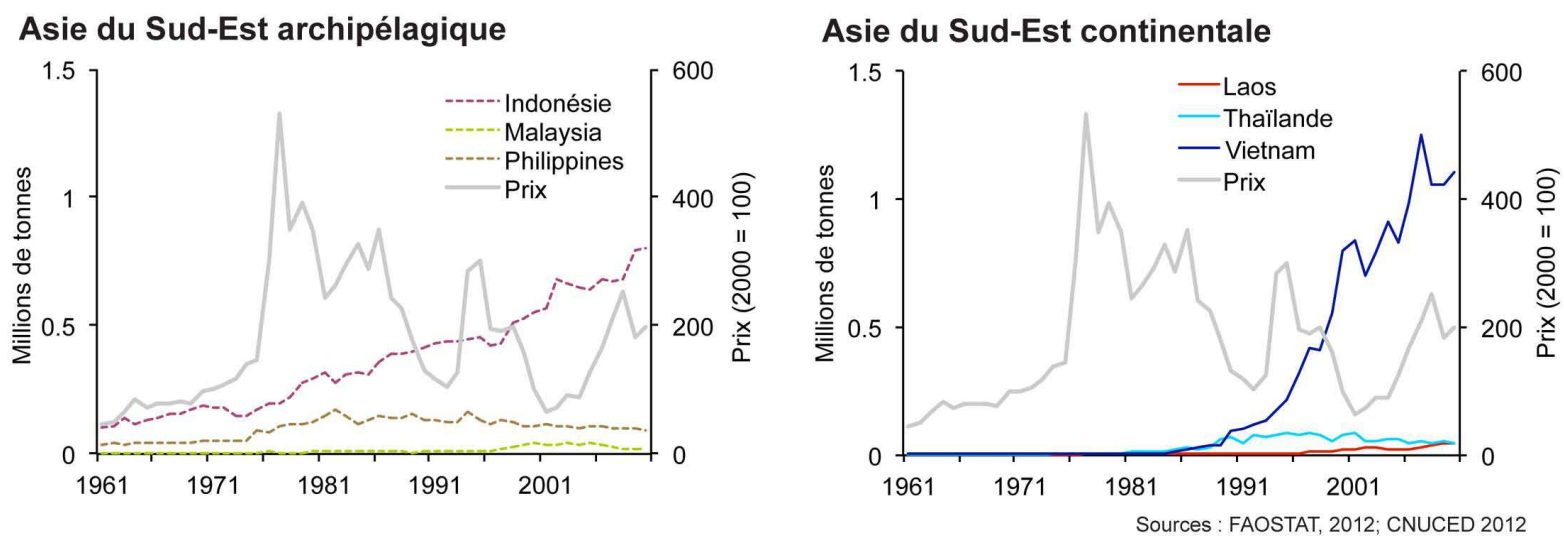

Figure 10 : Principaux producteurs de café et prix, 1961-2010

forte expansion en Malaysia à compter du tout début des années 1980, culminant en 1991 puis s'effondrant rapidement au cours des années suivantes, constituant ainsi l'archétypique d'un cycle dit de « boom and bust » (Kaur, 1995; Härdtner et al., 1997). C'est alors que l'Indonésie a commencé à prendre le relais, jusqu'à devenir aujourd'hui dans la région le seul producteur important d'une culture qui pour le moment demeure largement concentrée dans l'île de Sulawesi (Figures 11 et 12). Le cacao y est principalement cultivé par de petits producteurs parcellaires dont les revenus connaissent de fortes fluctuations. Ces fluctuations sont dues autant aux épidémies dévastatrices affectant régulièrement les plantations qu’à la volatilité du cours des fèves sur le marché mondial (Ruf, 1995 et 2000), celui-ci ayant connu une très forte baisse au cours des dernières décennies

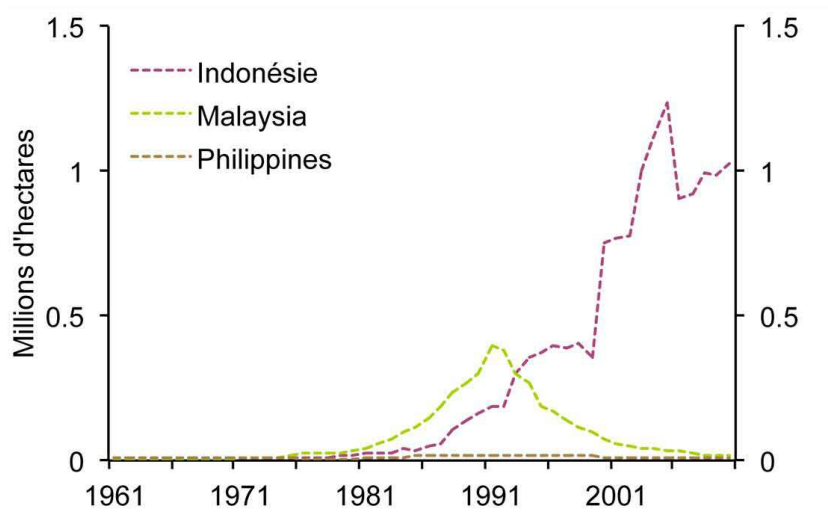

Source : FAOSTAT, 2012

Figure 11 : Superficies consacrées au cacao, principaux producteurs, 1961-2010

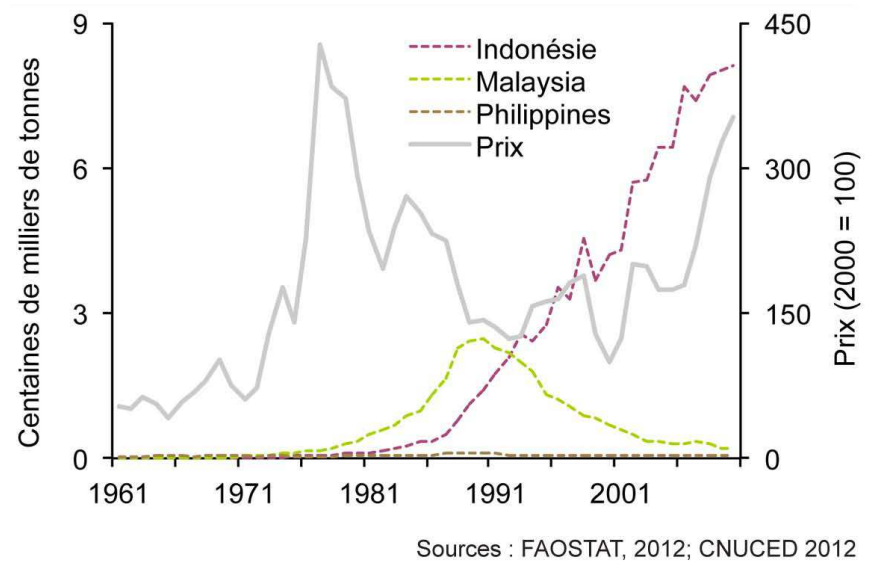

Figure 12 : Principaux producteurs de cacao et prix, 1961-2010 
du XXe siècle et une forte hausse depuis une dizaine d'années. Quoi qu'il en soit, les politiques de l'État indonésien continuent à favoriser l'expansion du cacaotier, l'objectif étant semble-t-il de permettre au pays de devenir le premier producteur mondial. En 2006, il a d'ailleurs atteint le second rang, devant le Ghana, mais pour le moment il demeure encore loin du premier, toujours occupé par la Côte d'Ivoire.

Si pour les petits producteurs parcellaires de cacao, la rentabilité à long terme est loin d'être garantie et qu'un bon nombre vivent dans la précarité, que dire des travailleurs dans les plantations de thé? Autre culture des hautes terres, produite depuis bien avant l'époque coloniale dans un Sud-Est asiatique à la confluence même des deux grands pays associés à la culture du thé, la Chine et l'Inde, son expansion n'en demeure pas moins elle aussi associée à l'histoire coloniale. Ainsi, en Indonésie, c'est encore une fois d'abord à Java, dans les hautes terres de sa partie occidentale, puis dans le nord de Sumatra que les Hollandais favorisèrent l'expansion de cette autre culture de rente à des fins d'exportation. À un point tel qu'en 1940 les plantations s'y étendaient sur plus de 200000 hectares (Etherington, 1974). Après la Deuxième Guerre mondiale et l'indépendance de l'Indonésie, et suite à la nationalisation des plantations hollandaises ainsi qu'à une forte chute des prix du thé sur le marché mondial, sa culture a connu un net recul dans l'archipel (Figures 13 et 14). Aujourd'hui, les travailleurs - surtout des femmes - des grandes plantations pour la plupart à nouveau privées comptent parmi les moins bien payés au pays, touchant des revenus dépassant à peine ceux des travailleurs rizicoles sans terre. Il n'y a donc plus que le Vietnam pour miser sur une forte expansion de la culture du thé, là aussi dans des hautes terres, celles tant du nord que du centre du pays. Le thé y est généralement de meilleure qualité que celui cultivé en Indonésie, où la croissance de la production repose désormais quasi-exclusivement sur la hausse des rendements. Mais, au total, au-delà de l'importance

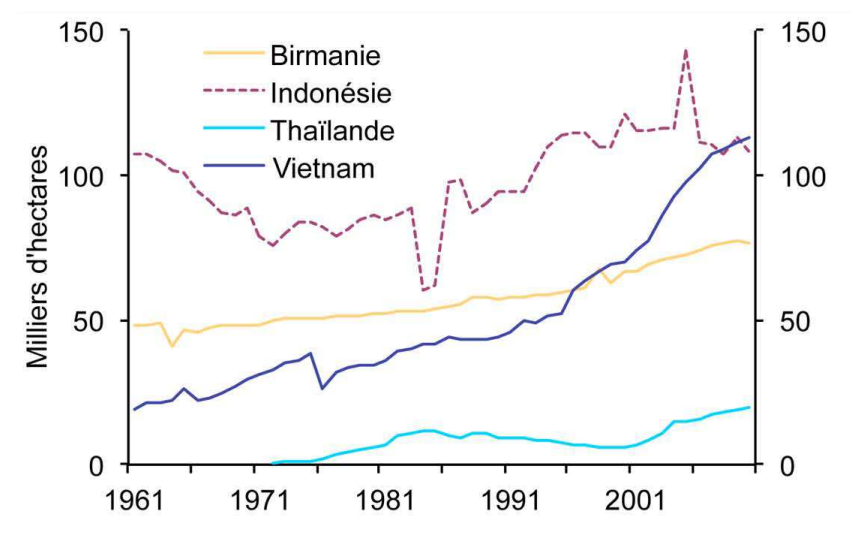

Source : FAOSTAT, 2012

Figure 13 : Superficies consacrées au théier, principaux producteurs, 1961-2010

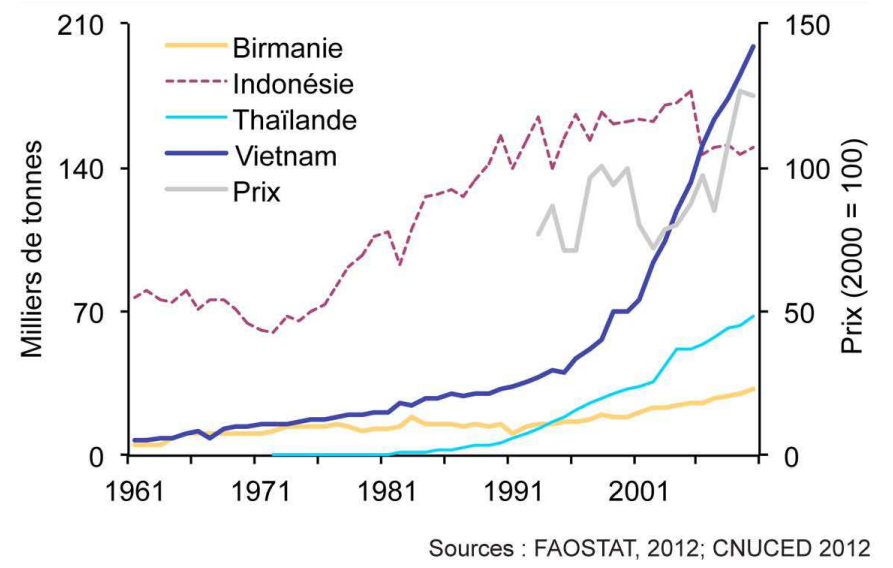

Figure 14 : Principaux producteurs de thé et prix, 1961-2010 
que sa culture représente dans les économies locales de plusieurs régions des quatre pays qui lui consacrent des portions non négligeables de leur territoire, les terres consacrées à la culture du thé à travers le Sud-Est asiatique apparaissent d'une taille relativement modeste par rapport à celles consacrées aux autres cultures commerciales.

Lesquelles comprennent celle du cocotier, dont près des deux tiers des terres qui lui sont consacrées dans le monde se trouvent en Asie du SudEst, essentiellement en Indonésie et aux Philippines (Figure 15), là où sa culture continue à s'étendre. Dans ce dernier pays, les cocoteraies couvrent tout près de $30 \%$ de l'ensemble des terres cultivées, étant entendu que, sous les cocotiers, diverses formes délevage peuvent être pratiquées. Au total, la part des terres de cet archipel qui leur est réservée est même supérieure à celle occupée par le maïs (23\% en 2008) et pas tellement inférieure aux surfaces rizicoles (37\%). Malgré la présence d'un bon nombre de moyennes et grandes plantations de cocotiers, ce sont les petits producteurs parcellaires qui assurent la plus grande partie de la récolte nationale. La taille moyenne des parcelles n'est que de 2,4 ha et leurs exploitants ne retirant généralement qu'une faible part de leur tout aussi faible revenu (Clarete et Roumasset, 1983). Au plan de la valeur commerciale, le principal produit de la noix de coco est l'huile extraite de son fruit, le coprah. Aux Philippines comme en Indonésie, il s'agit de la principale huile alimentaire consommée par la population. La plus grande partie de la production est néanmoins destinée à l'exportation, l'Asie du SudEst répondant depuis le début des années 1970 à plus $60 \%$ de la demande mondiale de coprah. Cela dit, la proportion de cette demande comblée

\section{Asie du Sud-Est archipélagique}

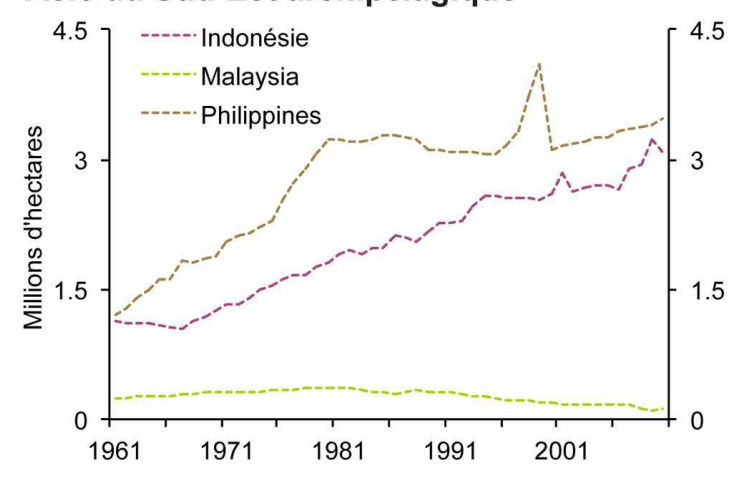

par l'Indonésie est destinée à s'accroître. D'une part, la culture du cocotier - tout comme celle de plusieurs autres plantes commerciales - y est en pleine expansion. D'autre part, l'huile de coprah (ou de coco) doit de plus en plus affronter sur le marché domestique indonésien la compétition de l'huile de palme, dont la production croît encore plus rapidement. Mais au total, plus que toutes les autres cultures de rente, le cocotier représente « a poor man's crop » (une culture pour les pauvres). Cette pauvreté concerne tout autant les petits producteurs parcellaires que les travailleurs des plantations, lesquels, appartenant souvent à ces mêmes familles de petits producteurs, ne reçoivent pour leur labeur qu'un très faible salaire.

Létalement du domaine agricole sud-est asiatique est donc d'abord fondé dans l'expansion des grandes cultures commerciales, auxquelles s'ajoute même celle la canne à sucre. Bien qu'à compter des années 1990, sa progression ait considérablement ralenti en Indonésie et aux Philippines, elle a depuis connu une forte progression au Vietnam et surtout en Thailande, ce qui représente un exemple additionnel de transfert de production. À vrai dire, dans l'ensemble de la région, l'expansion territoriale concerne la quasi-totalité des cultures, commerciales ou vivrières, même celle des légumes et plus encore des fruits. Le secteur paysan est responsable de la majeure partie de cette production de fruits et légumes - largement assurée dans les jardins de case - y compris celle des excédents, eux aussi en forte croissance et destinés à l'exportation.

Enfin, même l'élevage, essentiellement celui des volailles et des porcs, suit la tendance à la hausse, ayant débouché sur des poussées exportatrices massives de volailles par la Thailande, à compter

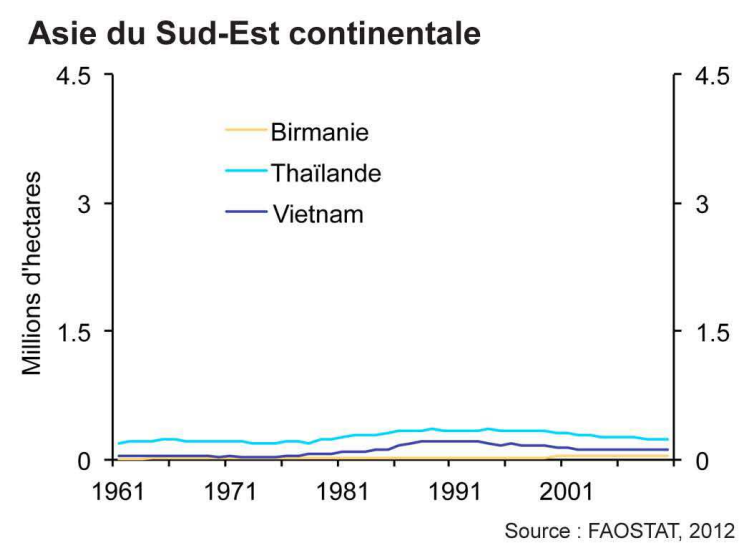

Figure 15 : Superficies consacrées au cocotier, principaux producteurs, 1961-2010 
des années 1980 et, plus modestement, de viande de porc par le Vietnam dès la fin de ces mêmes années. Mais l'une et l'autre poussée ont été brutalement interrompues, dans le premier cas par la grande crise aviaire de 2003 et dans le second par une épidémie de fièvre porcine amorcée deux ans plus tôt.

4. L'expansion agricole suscite d'intenses migrations de travail. On l'a vu, tant les pays que bien des régions à l'intérieur de ceux-ci font l'objet de transformations constantes de l'utilisation du sol agricole, des cultures déclinant voire disparaissant ici, alors qu'elles-mêmes ressurgissent là, parfois en compagnie de nouvelles cultures. Il en résulte une demande tous azimuts en force de travail : dans un contexte où la mécanisation du travail agricole demeure relativement faible, la plupart des cultures commerciales nécessitent des contingents de travailleurs importants. Les travailleurs migrants, saisonniers ou beaucoup plus souvent de longue durée, servent ainsi à combler des déficits locaux en main-d'œuvre. Ceux-ci peuvent être attribuables soit à la conquête par l'agriculture d'horizons marginaux, où les densités de population sont au départ insuffisantes pour répondre aux besoins de la filière; soit au désintérêt des populations locales pour le travail agricole salarié. Un tel désintérêt peut lui-même être attribué à des facteurs soit culturels, ce qui peut survenir parmi des populations minoritaires vivant dans les régions de hautes terres, soit sociaux. Ainsi, dans la péninsule malaise, où les emplois bien rémunérés dans les secteurs secondaire et tertiaire ne manquent pas, l'offre d'emplois agricoles faiblement rémunérés découlant de l'expansion agricole qui se poursuit rencontre peu d'intérêt parmi les populations locales disposant de sources de revenus suffisantes.

Dans tous les pays de la région, Laos excepté, cette expansion des terroirs agricoles vers les aires périphériques, la territorialisation des marges en quelque sorte, relève d'une stratégie à multiples volets. De nature démographique, économique et géopolitique, ceux-ci ont déjà fait l'objet de plusieurs analyses permettant de souligner le rôle clé que joue la paysannerie comme fer de lance territorial de l'État (De Koninck, 1986, 2000 et 2006; De Koninck et Déry, 1997). De plus, il est désormais démontré que l'objectif de redistribution et de déconcentration de la population poursuivi dans la région depuis au moins un demi-siècle, essentiellement par le biais de la colonisation agricole, demeure non seulement à l'avant-garde des dynamiques territoriales, mais qu'il est aussi généralement réalisé avec succès, du moins du strict de point de vue de cette déconcentration démographique (De Koninck et Pham, 2012).

5. Qui dit expansion agricole dit recul forestier. Ainsi, depuis le début des années 1960, la déforestation progresse dans tous les pays de la région à peu près au rythme de l'avancée des terres agricoles. Malgré les dénégations fréquentes des autorités, notamment au Vietnam, en Indonésie et en Malaysia, celles-ci ayant longtemps cherché à mettre la faute sur le dos des minorités ethniques pratiquant l'agriculture sur abattis-brûlis, c'est bel et bien l'expansion de l'agriculture commerciale qui est la principale responsable du recul forestier (Bernard et De Koninck, 1996) ${ }^{6}$. Certes, l'industrie forestière, qu'elle repose sur des coupes légales ou illégales, a son rôle à jouer (Van den Top, 2002). Mais depuis longtemps cette industrie évolue en étroite relation avec l'expansion des cultures (Kummer et Turner, 1994), laquelle repose sur et justifie tout à la fois le recours à la déforestation commerciale. Continuent de s'ensuivre des bavures majeures, tels ces grands incendies de forêts dont le Kalimantan indonésien, terre par excellence de l'expansion agricole, s'est fait une spécialité (Langner et al., 2007).

Complémentarités et relais caractérisent donc aussi les divers secteurs de l'industrie forestière. Ainsi, le Vietnam, qui au moins jusqu'au milieu des années 1990, avait largement pillé ses propres ressources, a depuis considérablement accru ses importations légales et illégales de produits forestiers en provenance de ses voisins laotien et cambodgien. Cela constitue un cas additionnel de ces transferts intra régionaux tant des responsabilités de production que des pressions environnementales qui s'ensuivent. Prenant leur origine à l'époque coloniale, de telles pratiques se sont grandement intensifiées depuis les années 1960. Le cas de la culture du palmier à huile en Malaysia et en Indonésie, facteur majeur de déforestation, fournit un autre exemple de complémentaritécompétition. D'une part, une partie importante des capitaux nécessaires à son expansion - en

6. La littérature sur la question de la responsabilité des minorités ethniques et de leurs pratiques agricoles dans le recul forestier est abondante. Dans l'ensemble cette littérature démontre que cette responsabilité est très réduite voire en général tout à fait marginale (Spencer, 1966; Dove, 1983; Thrupp et al., 1997; Fox, 2000; Cramb, 2007; Ducourtieux, 2009). 

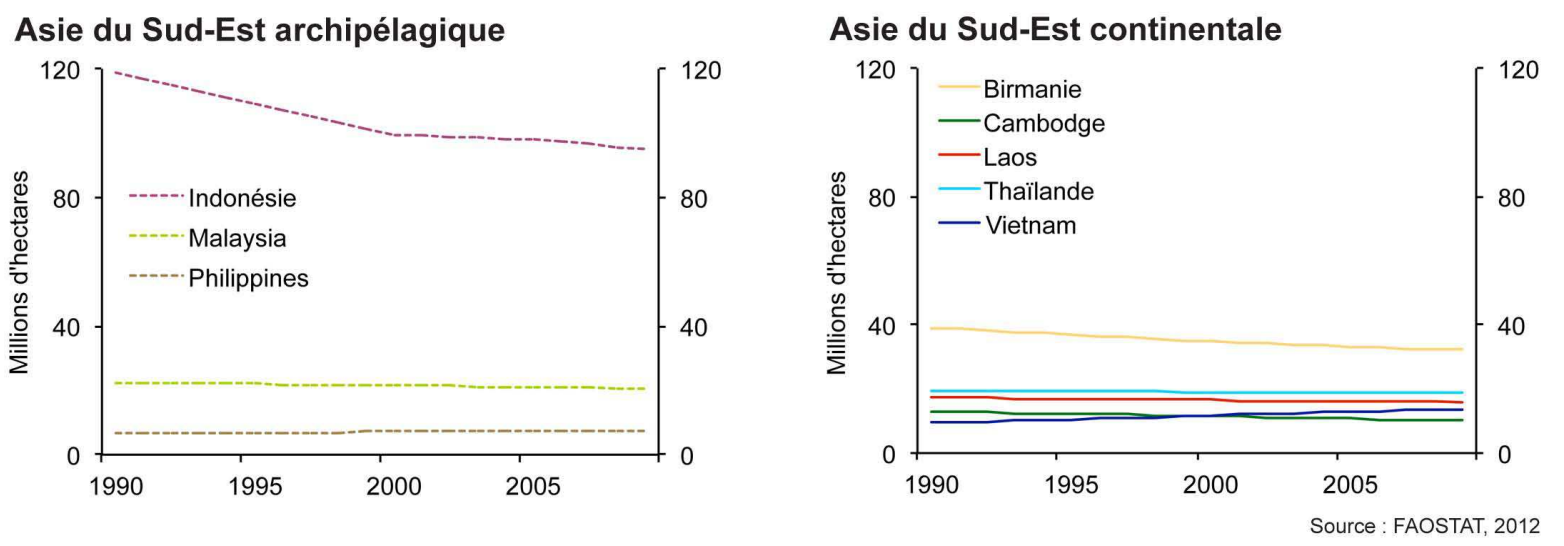

Figure 16 : Superficies forestières, 1990-2009

Indonésie d'abord mais aussi dans plusieurs autres pays, dont le Cambodge - provient d'entreprises multinationales basées en Malaysia. D'autre part, l'Indonésie elle, représente la principale origine des travailleurs migrants temporaires employés dans les plantations situées en territoire malaysien, là où l'on tente de ralentir le recul forestier, du moins dans la péninsule.

Cela dit, au moins un pays a entamé sa véritable transition forestière, i.e. celle qui consiste dans un arrêt voire un renversement du recul de la forêt. En effet, depuis la fin des années 1990, ceci expliquant cela, la Thailande a mis un terme à l'expansion de ses terroirs agricoles. Et depuis, alors que les données de la FAO indiquent une stabilisation du taux de couverture forestière autour de $28 \%$, divers indices indiquent une légère hausse de ce taux (Leblond, 2011). Quant au Vietnam, le recul de la forêt, encore très évident au début des années 1990 (De Koninck, 1997), y aurait alors été inversé de façon spectaculaire, à un point tel qu'aujourd'hui la couverture forestière serait en pleine expansion (Meyfroidt et Lambin, 2008). Dans la réalité, rien n'est moins sûr, quand on sait que l'expansion agricole vietnamienne est l'une des plus vigoureuses de toute la région et que, justement depuis les années 1990, elle se réalise surtout aux dépens des espaces forestiers. Aussi, les autorités vietnamiennes, à l'origine des données utilisées par la FAO, considèrent, à l'instar de plusieurs autres États, la plupart des cultures arbustives comme des forêts! Le Vietnam est aussi l'un des pays où la crevetticulture a le plus progressé au cours des dernières décennies, cette expansion s'étant réalisée essentiellement sur les littoraux du pays et aux dépens des forêts de mangrove.

6. L'expansion gagne le domaine maritime. Depuis les années 1960, non seulement les captures halieutiques se sont-elles accrues elles aussi à un rythme nettement supérieur à celui de la croissance démographique, mais la production provenant des activités d'aquaculture, tant continentale que littorale ou maritime - on parle alors de mariculture - a fait de même. Tout aussi significative a été la
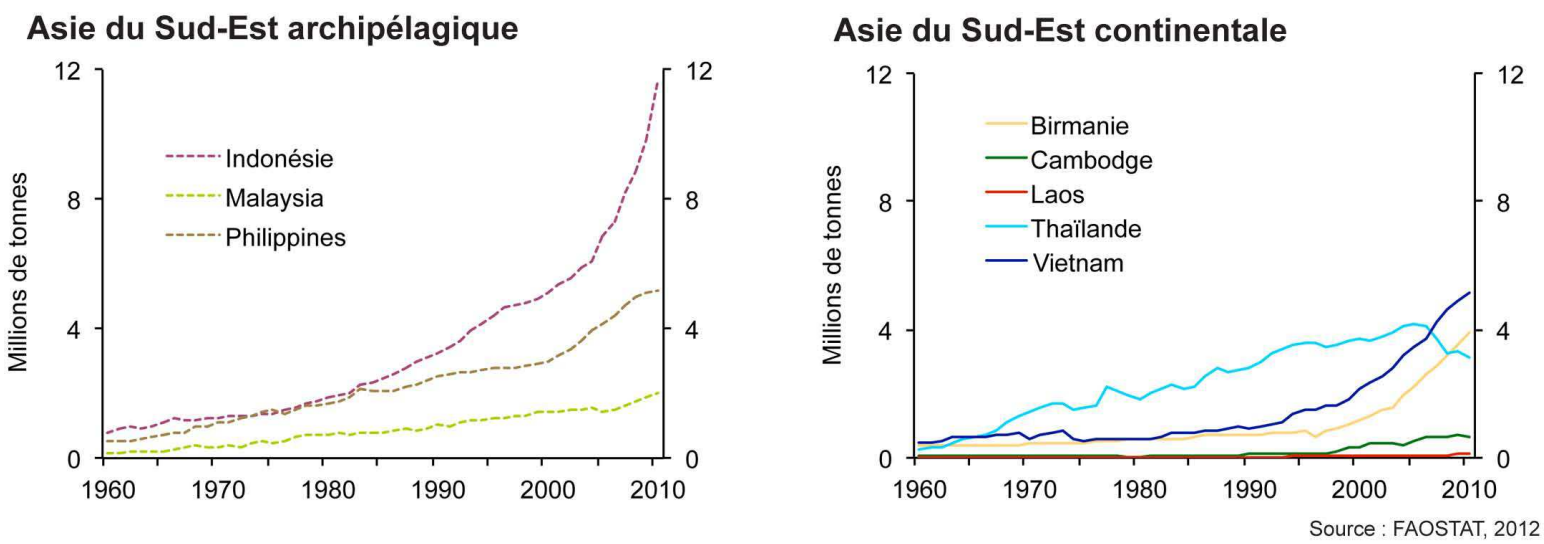

Figure 17 : Production de poissons et de fruits de mer, 1960-2010 

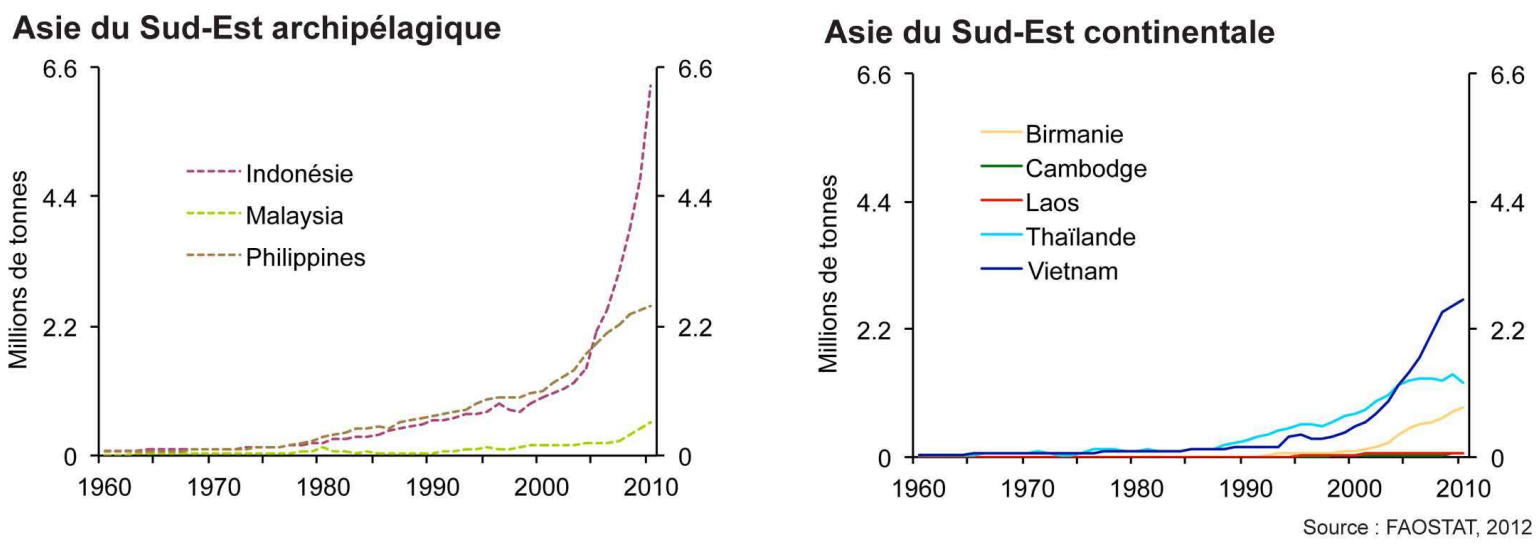

Figure 18 : Production aquacole, 1960-2010
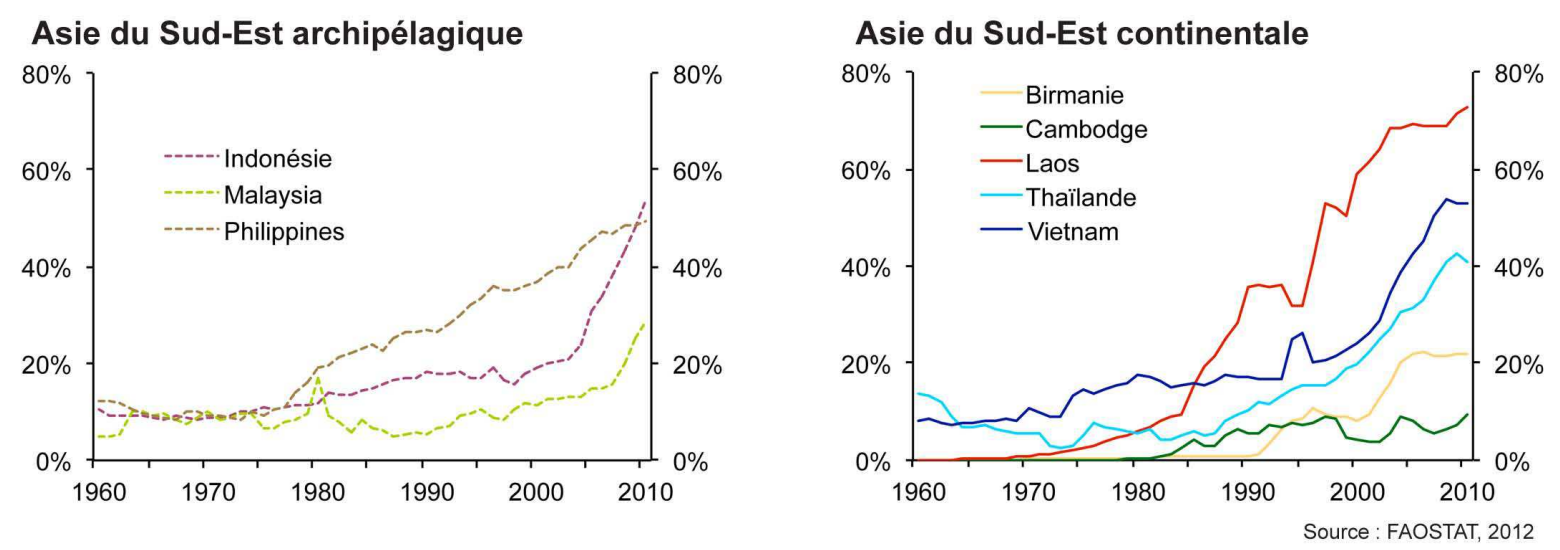

Figure 19 : Production de poissons et de fruits de mer issue de l'aquaculture, 1960-2010

croissance de la part de l'aquaculture - tous types d'environnement confondus ${ }^{7}$ - dans l'ensemble des productions marines et aquacoles, lesquelles comprennent de plus en plus les algues, cultivées à l'intérieur de vastes périmètres établis en haute mer. En conséquence, on assiste depuis 2008 à un véritable boom de l'ensemble des productions halieutiques dans la région (Figures 17, 18 et 19).

L'Indonésie et les Philippines, ces deux grands pays archipélagiques, représentent sans surprise les deux principaux producteurs, tant au chapitre des captures en mer qu'à celui de l'aquaculture. Pourtant, pour ce qui est des pêcheries, la Thailande, la Birmanie et le Vietnam talonnent désormais les Philippines, dans les deux derniers cas suite à une très forte croissance réalisée depuis les années 1990. D'ailleurs, le rattrapage économique tous azimuts du Vietnam, amorcé à compter de la deuxième moitié des années 1980, se manifeste également dans le domaine aquacole. Au Laos, pays enclavé, on assiste aussi à une augmentation significative de la part de l'aquaculture,

7. Ces types d'environnement sont les eaux douces, saumâtres et marines. la pêche proprement dite ne pouvant être pratiquée que dans les eaux du réseau hydrographique, lui-même centré sur le grand fleuve Mékong qui traverse la totalité de ce pays longiligne. Au Cambodge, les eaux du Mékong contribuent au dynamisme d'un secteur fondé dans la longue durée, celui de la pêche dans le Tonlé Sap, i.e. le Grand Lac. Pendant la majeure partie de l'année, son défluent se déverse dans le maître fleuve de l'Asie du Sud-Est continentale. Mais la rivière du Tonlé Sap inverse son cours, lorsque ses eaux sont refoulées par les crues du Mékong, au moment où celles-ci culminent, généralement à compter de septembre ou octobre. Cependant, l'exceptionnelle productivité des eaux du Grand Lac, qui chaque année pouvait multiplier sa superficie par six, formant ainsi le lac le plus fécond du monde pour la pêche (Van Zalinge et al., 2001), est aujourd'hui largement remise en question par deux facteurs. Il s'agit en premier lieu de la déforestation excessive dont a fait l'objet depuis les années 1970 la forêt riparienne qui ceinture le lac et qui en accueille les débordements. Cette écologie est aussi menacée, en second lieu, par le dérèglement du calendrier et du rythme de ces débordements, 
tout comme par la réduction de leur ampleur, à la suite du harnachement hydroélectrique du cours principal du Haut-Mékong dans la province chinoise du Yunnan, et celui de ses grands affluents, notamment laotiens (Hirsch, 2010).

S'agissant des pressions et risques environnementaux associés à l'intensification et à l'expansion des productions agricoles et aquacoles, celle des crevettes apparaît particulièrement critique. En effet, l'expansion de la crevetticulture se réalise largement aux dépens des forêts de mangrove. Cette forme d'élevage qui répond à une forte hausse de la demande tant domestique qu'extérieure, repose sur une intensification à caractère quasi industriel : des casiers sont aménagés à même les littoraux préalablement débarrassés de leurs forêts naturelles de mangrove dont la fonction de sas et de viviers naturels est ainsi annihilée. Dans ces casiers, qui correspondent à de vastes aquariums très densément peuplés, les crevettes font l'objet d'une véritable embouche, alors que les épizooties que risque d'entraîner leur entassement extrême sont contrôlées par le recours massif aux antibiotiques.

Ces casiers littoraux, qui déversent d'importantes quantités d'antibiotiques et de déchets issus de l'élevage intensif des crevettes, contribuent à polluer les eaux littorales et à en décimer la faune, contraignant ainsi les petits pêcheurs à s'éloigner de plus en plus des rivages. Cette pollution maritime s'additionne à celle attribuable à l'essor des casiers flottants, lesquels se répandent désormais dans la plupart des mers de la région et en particulier dans celles des Philippines et de l'Indonésie. Ainsi à la pression sur les terres s'ajoute celle sur les mers, avec des conséquences environnementales dont la sévérité ne cesse de s'amplifier (Sodhi et al., 2011).

Encore aujourd'hui, avec le tiers des superficies de mangrove dans le monde (Spalding et al. 2010), dont plus de la moitié pour la seule Indonésie, la région est celle qui possède le plus important patrimoine. Mais c'est aussi celle où ce patrimoine recule le plus rapidement. Ainsi, entre 1980 et 2005, soit en moins de trois décennies, la superficie des mangroves du Sud-Est asiatique a régressé de près de $30 \%$, donc à un rythme encore plus rapide que les forêts proprement continentales. Et ici aussi, les relais et complémentarités sont opérationnels, le Vietnam s'étant récemment joint à l'Indonésie à titre de frontière particulièrement active (Hishamunda et al., 2009).

\section{Produire pour tous les marchés}

L'augmentation de toutes ces productions apparaît d'autant plus significative - qu'elles proviennent de l'agriculture, de l'aquaculture ou de la pêche, qu'il s'agisse de cultures vivrières ou commerciales, de celles qui sont destinées aux marchés domestiques ou à l'exportation - que dans pratiquement chaque pays elle a été plus rapide, on l'a déjà évoqué, que la croissance démographique.

Depuis 1960, la valeur de l'ensemble de la production agricole sud-est asiatique a cru presque deux fois plus rapidement que celle du reste du monde, cette contribution sélevant aussi plus rapidement que la part de la population régionale dans celle du monde. Il en est résulté non seulement une hausse de l'autosuffisance vivrière, du moins à l'échelle de l'ensemble du Sud-Est asiatique, mais aussi un accroissement de la part de la région dans le commerce agricole mondial. Cette présence accrue sur les marchés mondiaux des productions agricoles sud-est asiatiques, tant vivrières que commerciales, est donc d'abord attribuable à des politiques étatiques, largement partagées à travers la région. Ces politiques ont presque partout, est-il nécessaire de le rappeler, consisté dans un appui multiforme à l'intensification agricole in situ, en association avec une expansion territoriale tous azimuts, littéralement terrestre et maritime. De plus, s'agissant des exportations des produits de la terre et de la mer, ce ne sont pas les débouchés qui manquent. Dans ce domaine, comme dans celui des exportations de matières premières minières et forestières, la forte croissance industrielle et économique des partenaires asiatiques, en particulier ceux d'Asie de l'Est, est garante d'une hausse soutenue de la demande.

Enfin, la complémentarité entre les pays de la région et peut-être plus encore le jeu des transferts réalisés entre eux quant aux responsabilités de production contribuent à soutenir la présence et la compétitivité de leurs exportations sur les marchés régionaux et mondiaux.

\section{Un pari sur la terre et sur la mer à la merci de la privatisation}

Il semble bien évident que dans l'ensemble du Sud-Est asiatique, en particulier depuis un demisiècle, afin de répondre aux défis de la croissance économique et de l'amélioration des niveaux de vie, on en soit arrivé à parier, à miser sur la terre et 
sur la mer, audacieusement et de façon répétitive, en $\mathrm{y}$ intensifiant et en y étendant un très large éventail de productions. À cet égard, quelques constats et commentaires s'imposent.

1. Cette dynamique s'est installée dans une région qui ne déroge pas à la tendance quasi universelle à l'urbanisation, le taux de population urbaine $\mathrm{y}$ étant passé, entre 1950, 1975, 2000 et 2011, de $15 \%$ à $23 \%$ puis à $38 \%$ et quelque $44 \%$ (UNPOP 2012), la Malaysia et les Philippines ayant depuis longtemps franchi ce seuil. Longtemps parasitaire, au moins jusqu'à la fin des années 1960 dans la plupart des pays, cette urbanisation est devenue de plus en plus associée à l'industrialisation, la Malaysia en représentant l'exemple le plus achevé.

2. L'agriculture continue à jouer un rôle moteur essentiel dans le développement économique, au-delà du recul de la part de sa contribution au PIB et à l'emploi. D'ailleurs, cette part de l'emploi assurée par l'agriculture demeure relativement élevée dans six des huit pays examinés ici, s'y situant en 2010 entre 41\% (Indonésie) et 75\% (Laos). En Malaysia et aux Philippines, là où l'industrialisation est déjà beaucoup plus importante, elle est désormais inférieure à 13 et $34 \%$. Pourtant, rappelons-le, dans ces deux pays aussi, l'expansion des terroirs agricoles se poursuit (Figures 4 et 5).

3. Le dynamisme de l'agriculture, tel qu'il se manifeste par l'intensification, l'expansion territoriale et la hausse de la production apparaitt largement partagé entre le secteur paysan et celui des plantations, entre petits, moyens et grands producteurs. Certes des différences non négligeables existent en fonction des cultures concernées, mais les grandes entreprises agricoles sont loin dêtre les seules à être productives et à sétendre (Feintrenie, 2011).

4. Un tel équilibre, par ailleurs relatif et de plus en plus instable, est fondamentalement attribuable, aux politiques très interventionnistes des États qui, jusqu'à très récemment, ont favorisé et contrôlé les investissements dans le secteur agricole. Parmi les meilleurs exemples de ces politiques, on peut évoquer les immenses investissements dans les infrastructures et les techniques de la révolution verte, ce qui comprend la diffusion subventionnée de ces dernières auprès des paysanneries. Certes, cet appui de l'État n'a pas été uniforme - ainsi, en Thaillande, il a surtout concerné les infrastructures d'irrigation (Figure 2). Aussi, il n'a pas suivi les mêmes calendriers, des pays tels le Laos et le Cambodge ayant accumulé quelque retard, encore que, comme on l'a vu, la croissance des rendements rizicoles et de la production est enfin, là aussi, au rendez-vous (Figures 1 et 3 ).

5. Au sujet des équilibres ou plus exactement des déséquilibres, ceux-ci se manifestent de façon de plus en plus évidente au plan environnemental comme en témoignent le recul accéléré du patrimoine forestier (Figure 16), notamment sur les littoraux, ainsi que la pollution croissante des espaces maritimes, dont la productivité halieutique même est ainsi mise en péril. La question centrale est ici celle des limites au-delà desquelles le pari sur la terre et la mer deviendra trop risqué pour être poursuivi.

6. Mais au total, le problème ou plutôt les problèmes qui apparaissent depuis peu comme les plus sérieux, les plus menaçants pour le modèle de développement agricole sud-est asiatique sont sa privatisation récente et accélérée ainsi que les conséquences qui en découlent pour les populations. Partout, l'État se désengage. Ce désengagement prend plusieurs formes. Premièrement, l'expansion des terroirs agricoles est de moins en moins déterminée et contrôlée par les politiques publiques mais de plus en plus par les entreprises multinationales. C'est largement le cas des cultures de rente, crevetticulture comprise (Yap et al., 2007).

Deuxièmement, tant les objectifs de cette expansion, tels ceux qui consistaient à réduire la pauvreté paysanne par le prélèvement migratoire planifié et l'ouverture des fronts pionniers, ou ceux d'un financement systématique de l'intensification agricole au sein de la petite paysannerie, ces objectifs disons-nous apparaissent de plus en plus remplacés par ceux dictés par le marché, y compris celui des agrocarburants qui a l'huile de palme dans sa mire depuis un bon moment (De Koninck et al., 2011). Car, troisièmement, presque partout dans la région, la responsabilité de l'ouverture de nouvelles terres à l'agriculture, qu'il s'agisse ou non de fronts pionniers, est désormais de plus en plus entre les mains d'entreprises multinationales, notamment malaysiennes et thailandaises. De plus il semble bien que ce soit des intérêts chinois qui coordonnent, si l'on peut dire, l'expansion de la culture de l'hévéa dans le nord du Laos (Mann, 2009). Ce sont désormais les entreprises qui gèrent la frontière agricole. En conséquence, quatrièmement, les migrations, tant 
locales que nationales et internationales, en particulier celles qui accompagnent l'expansion agricole, notamment à Bornéo, du côté tant malaysien qu'indonésien, sont celles de travailleurs sans terre et non plus de colons. Cinquièmement, leurs déplacements ne sont plus appuyés par l'État alors que les salaires, généralement très faibles, facilitent le maintien de la rentabilité des plantations.

7. Bien sûr des résistances apparaissent, y compris au sein même des communautés qui parviennent à tirer profit du dynamisme économique ambiant, particulièrement celui de l'agriculture (Bissonnette, 2011; Cramb, 2011; Hall et al., 2011; Feintrenie, 2011; Rigg et Vandergeest, 2012). Mais au total, le pouvoir d'attribution foncière, $\mathrm{y}$ compris par l'accaparement des terres qui s'accentue dans la région, en particulier en Indonésie, aux Philippines (pourtant très densément peuplées) et au Cambodge, semble glisser inexorablement vers les entreprises privées, de plus en plus multinationales. L'un des meilleurs indices en est sans doute qu'à l'échelle de l'ensemble de la région, au plan des superficies, la part des cultures de rente, pour la plupart très largement orientées vers les marchés d'exploitation, progresse plus rapidement que celle des cultures vivrières, quant à elles très largement orientées vers le marché domestique. Ce lent mais apparemment inexorable transfert du contrôle de la production agricole hors des mains des États et des paysans vers celles des grandes entreprises ne répond-il pas à une sorte de renaissance de la logique de la concentration de l'agriculture, via celle des terres, réhabilitées à titre de moyen de production? En tout cas, on est en droit de craindre une dérive de la fuite en avant des agricultures sud-est asiatiques, à un point tel qu'elle se réaliserait désormais au détriment des intérêts des populations locales.

\section{Références}

Barker R., Herdt R.W. et Rose B. (1985). The Rice Economy of Asia. Washington, D.C.: Resources for the Future, $356 \mathrm{p}$.

Bernard S. et De Koninck R. (1996). «The retreat of the forest in Southeast Asia: a cartographical assessment ». Singapore Journal of Tropical Geography, 1, p. 1-14.

Bissonnette J.-F. (2011). " Claiming Territories, Defending Livelihoods: The Struggle of Iban communities in Sarawak ». In De Koninck R., Bernard S. et Bissonette J.-F. (dir.),
Borneo Transformed. Agricultural Expansion on the Southeast Asian Frontier. NUS Press: Singapour, p. 10-43.

Clarete R. et Roumasset J.-A. (1983). An Analysis of Economic Policies Affecting the Philippine Coconut Industry. Philippine Institute for Development Studies, 66 p.

Cramb Rob A. (2007). Land and Longhouse: Agrarian Transformation in the Uplands of Sarawak. Copenhague: NIAS, $422 \mathrm{p}$.

Cramb Rob A. (2011). « Agrarian Transitions in Sarawak : Intensification and Expansion Reconsidered ». In De Koninck R., Bernard S. et Bissonette J.-F. (dir.), Borneo Transformed. Agricultural Expansion on the Southeast Asian Frontier. NUS Press: Singapour, p. 44-93.

De Koninck R. (1986). « La paysannerie comme fer de lance territorial de l'État: le cas de la Malaysia ». Cabiers des Sciences Humaines (ORSTOM), 22, 3-4, p. 355-370.

De Koninck R. (1997). Le recul de la forêt au Vietnam. Ottawa: CRDI, 97 p.

De Koninck R. (2000). «The Theory and Practice of Frontier Development : Vietnam's Contribution ", Asia Pacific Viewpoint, 41, 1, p. 7-21.

De Koninck R. (2006). « On the Geopolitics of Land Colonization: Order and Disorder on the Frontiers of Vietnam and Indonesia ». Moussons 9-10: 33-59.

De Koninck R. (2011). « Southeast Asian Agricultural Expansion in Global Perspective », In De Koninck R., Bernard S. et Bissonette J.-F. (dir.), Borneo Transformed. Agricultural Expansion on the Southeast Asian Frontier. NUS Press: Singapour, p. 1-9.

De Koninck R. et Déry S. (1997). « Agricultural Expansion as a Tool of Population Redistribution in Southeast Asia ". Journal of Southeast Asian Studies, 21, 1, p. 1-26.

De Koninck R., Bernard S. et Bissonette J.-F. (dir.), (2011). Borneo Transformed. Agricultural Expansion on the Southeast Asian Frontier. NUS Press: Singapour, 216 p.

De Koninck R. et Pham Thanh Hai (2012). "Comment mesurer la redistribution de la population en Asie du Sud-Est? ", communication présentée dans le cadre du Colloque international « $\mathrm{La}$ mesure du développement 
", GEMDEV-UNESCO, Paris, février 2012. http://www.gemdev.org/publications/com mesure_dev.htm

De Koninck R. et Rousseau J.-F. (2012). Gambling with the Land. The Contemporary Evolution of Southeast Asian Agriculture. Singapour: NUS Press, sous presse.

Dove M. (1983). « Theories of swidden agriculture and the political economy of ignorance ». Agroforestry Systems, 1, p. 85-99.

Ducourtieux O. (2009). Du riz et des arbres L'interdiction de l'agriculture d'abattis-brûlis, une constante politique au Laos. Paris : IRD - Karthala, $376 \mathrm{p}$.

Etherington D. M. (1974). «The Indonesian Tea Industry ». Bulletin of Indonesian Economic Studies, 10, 2, p. 83-113.

Feintrenie L. (2010) Entre forêts, agroforêts et plantations: Analyse des dynamiques paysagères à Bungo, province de Jambi, Indonésie, Thèse de doctorat non publiée, Université Paul Valéry-Montpellier 3, 2 volumes, 163 et $142 \mathrm{p}$.

Fortunel F. (2000). Le café au Vietnam. De la colonisation à l'essor d'un grand producteur mondial. Paris : L'Harmattan, $172 \mathrm{p}$.

Fox J. M. (2000). «How Blaming 'Slash and Burn' Farmers Is Deforesting Mainland Southeast Asia ", Asia Pacific Issues, 47 (Honolulu: EastWest Center), 8 p.

Geertz C. (1963). Agricultural Involution: The Process of Ecological Change in Indonesia. Berkeley et Los Angeles: University of California Press, $196 \mathrm{p}$.

Hall D., Hirsch P. et Li T. (2011). Powers of Exclusion. Land Dilemmas in Southeast Asia. Singapour: NUS Press, 266 p.

Härdter R., Woo Yin Chow et Ooi Soo Hock (1997). «Intensive Plantation Cropping, a Source of Sustainable Food and Energy Production in the Tropical Rain Forest Areas in Southeast Asia ». Forest Ecology and Management, 93, p. 93-102.

Hardy A. (2003). Red Hills : Migrants and the State in the Highlands of Vietnam. Honolulu: University of Hawaii Press, 384 p.

Hirsh P. (2010). « The Changing Political Dynamics of Dam Building on the Mekong ". Water Alternatives 3, 2, p. 312-323.
Hishamunda N., Bueno P. B., Ridler N, et Yap W. G. (2009). Analysis of Aquaculture Development in Southeast Asia. A Policy Perspective. Rome : FAO Fisheries and Aquaculture, 69 p..

Kaur A. (1995). «The Origins of Cocoa in Malaysia ". Journal of the Malaysian Branch, Royal Asiatic Society (JMBRAS), 68, 1, p. 67-80.

Kummer D. M. and Turner B. L. (1994). « The Human causes of Deforestation in Southeast Asia. The recurrent pattern is that of large-scale logging for exports, followed by agricultural expansion ». Bioscience, 44, 5, p. 323-28.

Langner A., Miettinen J. et Siegert F. (2007). « Land cover change 2002-2005 in Borneo and the role of fire derived from MODIS imagery ». Global Change Biology, 11, p. 2329-2340.

Leblond J.-Ph. (2011). Vers une transition forestière en Thaïlande. Thèse de doctorat non publiée, Université de Montréal, 622 p.

Mann C. C. (2009). «Addicted to Rubber». Science, 325, p. 564-566.

Meyfroidt, P., \& Lambin, E. F. (2008). «The causes of the reforestation in Vietnam ». Land $U_{s e}$ Policy, 25, 2, p. 182-197.

Neilson J. (2008). « Global Private Regulation and Value-Chain Restructuring in Indonesian Smallholder Coffee Systems ", World Development, 36, 9, p. 1607-22.

Potter L. (2011). "Agrarian Transitions in Sarawak : Characteristics, Limitations and Accomodations ", In De Koninck R., Bernard S. et Bissonette J.-F. (dir.), Borneo Transformed. Agricultural Expansion on the Southeast Asian Frontier. NUS Press: Singapour, p. 152-202.

Rigg J. et Vandergeest P. (dir.) (2012). Revisiting Rural Places. Pathways to Poverty and Prosperity in Southeast Asia. Singapour: NUS Press, 376 p.

Ruf F. (1995). Booms et crises du cacao. Les vertiges de l'or brun. Paris: Karthala, 459 p.

Ruf F. (2000). « L'avenir des cultures pérennes en Indonésie. Cacao et clou de girofle après la tempête monétaire ». Tiers Monde, 41, 162, p. 431-52.

Spalding M, Kainuma K. et Collins L. (2010) World Atlas of Mangroves. Earthscan publications, $319 \mathrm{p}$. 
Spencer J. E. (1966). Shifting Cultivation in Southeastern Asia. Berkeley: University of California Press, $247 \mathrm{p}$.

Sodhi N., Posa M., Lee T., Bickford D., Koh L. et Brook B. (2010) «The State and Conservation of Southeast Asian Biodiversity ». Biodiversity and Conservation, 19, 2, p. 317-28.

Thrupp L. A., Hecht S. B. et Browder J. O. (1997). The Diversity and Dynamics of Shifting Cultivation: Myths, Realities and Policy Implications, Washington: World Resource Institute, 48 p.

Van den Top, G. (2002). The Social Dynamics of Deforestation in the Philippines: Actions, Options and Motivations. Copenhague: NIAS, $389 \mathrm{p}$.

Yap W. G., Smith S. F., Rimmer M., Phillips M. J., Sih Yang Sim, Kongkeo H. et Bueno P. B. (2007). Aquaculture in Asia-Pacific and the Outlook for Mariculture in Southeast Asia. http://library. enaca.org/NACA-Publications/Overview_of Aquaculture.pdf.

\section{Liste des illustrations}

Carte 1. L'Asie du Sud-Est

Tableau 1. Pourcentage des superficies nationales consacrées à l'agriculture, 1961-2009

Tableau 2. Superficies consacrées aux principales cultures, 1961-2010

Figure 1. Rendements rizicoles, 1961-2010

Figure 2. Superficie équipée de systèmes d'irrigation, 1961-2009

Figure 3. Production rizicole et prix, 1961-2010

Figure 4. Superficie agricole, 1961-2009

Figure 5. Croissance relative des superficies agricoles, 1961-2009

Figure 6. Superficies consacrées au palmier à huile, principaux producteurs, 1961-2010

Figure 7. Superficies consacrées à l’hévéa, principaux producteurs, 1961-2010

Figure 8. Superficies consacrées au café, 1961-2010

Figure 9. Rendements caféiers, 1961-2010

Figure 10. Principaux producteurs de café et prix, 1961-2010

Figure 11. Superficies consacrées au cacao, principaux producteurs, 1961-2010
Figure 12. Principaux producteurs de cacao et prix, 1961-2010

Figure 13. Superficies consacrées au théier, principaux producteurs, 1961-2010

Figure 14. Principaux producteurs de thé et prix, 1961-2010

Figure 15. Superficies consacrées au cocotier, principaux producteurs, 1961-2010

Figure 16. Superficies forestières, 1990-2009

Figure 17. Production de poissons et de fruits de mer, 1960-2010

Figure 18. Production aquacole, 1960-2010

Figure 19. Production de poissons et de fruits de mer issue de l'aquaculture, 1960-2010 


\section{Dernières parutions}

\section{Working Papers}

Hervé Le Bras, Jean-Luc Racine \& Michel Wieviorka, National Debates on Race Statistics: towards an International Comparison, FMSH-WP-2012-01, février 2012.

Manuel Castells, Ni dieu ni maître : les réseaux, FMSH-WP-2012-02, février 2012.

François Jullien, L'écart et l'entre. Ou comment penser l'altérité, FMSH-WP-2012-03, février 2012.

Itamar Rabinovich, The Web of Relationship, FMSH-WP-2012-04, février 2012.

Bruno Maggi, Interpréter l'agir : un défi théorique, FMSH-WP-2012-05, février 2012.

Pierre Salama, Chine - Brésil : industrialisation et "désindustrialisation précoce », FMSH-WP-2012-06, mars 2012.

Guilhem Fabre \& Stéphane Grumbach, The World upside down, China's RED and innovation strategy, FMSH-WP-2012-07, avril 2012.

Joy Y. Zhang, The De-nationalization and Re-nationalization of the Life Sciences in China: A Cosmopolitan Practicality?, FMSH-WP-2012-08, avril 2012.

John P. Sullivan, From Drug Wars to Criminal Insurgency: Mexican Cartels, Criminal Enclaves and Criminal Insurgency in Mexico and Central America. Implications for Global Security, FMSH-WP-2012-09, avril 2012.

Marc Fleurbaey, Economics is not what you think: A defense of the economic approach to taxation, FMSHWP-2012-10, may 2012.

Marc Fleurbaey, The Facets of Exploitation, FMSH-WP-2012-11, may 2012.

Jacques Sapir, Pour l'Euro, l'heure du bilan a sonné: Quinze leçons et six conclusions, FMSH-WP-2012-12, juin 2012.

Rodolphe De Koninck \& Jean-François Rousseau, Pourquoi et jusquioù la fuite en avant des agricultures sud-est asiatiques?, FMSH-WP-2012-13, juin 2012.

\section{Position Papers}

Jean-François Sabouret, Mars 2012 : Un an après Fukushima, le Japon entre catastrophes et résilience, FMSH-PP-2012-01, mars 2012.

Ajay K. Mehra, Public Security and the Indian State, FMSH-PP-2012-02, mars 2012.

Timm Beichelt, La nouvelle politique européenne de l'Allemagne : L'émergence de modèles de légitimité en concurrence?, FMSH-PP-2012-03, mars 2012.

Informations et soumission des textes : wpfmsh@msh-paris.fr

http://halshs.archives-ouvertes.fr/FMSH-WP

http://wpfmsh.hypotheses.org 